\title{
Assessing the provisioning potential of ecosystem services in a Scandinavian boreal forest : Suitability and tradeoff analyses on grid-based wall-to-wall forest inventory data
}

\section{Vauhkonen, Jari}

2017-04-01

\begin{abstract}
Vauhkonen , J \& Ruotsalainen , R 2017 , ' Assessing the provisioning potential of ecosystem services in a Scandinavian boreal forest : Suitability and tradeoff analyses on grid-based wall-to-wall forest inventory data ' , Forest Ecology and Management, vol. 389 , pp. 272-284 . https://doi.org/10.1016/j.foreco.2016.12.005
\end{abstract}

http://hdl.handle.net/10138/297782

https://doi.org/10.1016/j.foreco.2016.12.005

$$
\begin{aligned}
& \text { cc_by_nc_nd } \\
& \text { acceptedVersion }
\end{aligned}
$$

Downloaded from Helda, University of Helsinki institutional repository.

This is an electronic reprint of the original article.

This reprint may differ from the original in pagination and typographic detail.

Please cite the original version. 
1 Full Length Article

2

3 Title

4 Assessing the provisioning potential of ecosystem services in a Scandinavian boreal forest:

5 suitability and tradeoff analyses on grid-based wall-to-wall forest inventory data

6

7 Authors

8 Jari Vauhkonen* \& Roope Ruotsalainen

9

10 Affiliation (both authors):

11 - University of Eastern Finland, School of Forest Sciences, Yliopistokatu 7 (P.O. Box 111), FI-80101

12 Joensuu, Finland

13 - University of Helsinki, Department of Forest Sciences, Latokartanonkaari 7 (P.O. Box 27), FI-00014

14 Helsinki, Finland

15

16

* Corresponding author. Present address: Natural Resources Institute Finland (Luke), Economics and

17 Society, Yliopistokatu 6, FI-80100 Joensuu, Finland. E-mail jari.vauhkonen@luke.fi

18

19 Disclaimer:

20

This is an author's version of a manuscript, which was submitted to peer-review and subsequently

21 accepted for publication in Forest Ecology and Management (publisher: Elsevier, Inc.). The journal

22 version differs from this pre-print and the text should only be quoted by accessing the final version

23 following the DOI 10.1016/j.foreco.2016.12.005 


\section{Abstract}

Determining optimal forest management to provide multiple goods and services, also referred to as Ecosystem Services (ESs), requires operational-scale information on the suitability of the forest for the provisioning of various ESs. Remote sensing allows wall-to-wall assessments and provides pixel data for a flexible composition of the management units. The purpose of this study was to incorporate models of ES provisioning potential in a spatial prioritization framework and to assess the pixel-level allocation of the land use. We tessellated the forested area in a landscape of altogether 7,500 ha to 27,595 pixels of $48 \times 48 \mathrm{~m}^{2}$ and modeled the potential of each pixel to provide biodiversity, timber, carbon storage, and recreational amenities as indicators of supporting, provisioning, regulating, and cultural ESs, respectively. We analyzed spatial overlaps between the individual ESs, the potential to provide multiple ESs, and tradeoffs due to production constraints in a fraction of the landscape. The pixels considered most important for the individual ESs overlapped as much as $78 \%$ between carbon storage and timber production and up to $52.5 \%$ between the other ESs. The potential for multiple ESs could be largely explained in terms of forest structure as being emphasized to sparsely populated, spruce-dominated old forests with large average tree size. Constraining the production of the ESs in the landscape based on the priority maps, however, resulted in sub-optimal choices compared to an optimized production. Even though the land-use planning cannot be completed without involving the stakeholders' preferences, we conclude that the workflow described in this paper produced valuable information on the overlaps and tradeoffs of the ESs for the related decision support.

Keywords: Forest inventory; Remote sensing; Spatial multi-criteria decision analysis; Multi-attribute utility theory; Zonation 


\section{Introduction}

Forest bioeconomy stimulates new industries to replace fossil-based materials using forest biomass for products such as bioenergy, chemicals, polymers, and wood-based structures (Puddister et al., 2011; Hannerz et al., 2014). The increased requirements to use forest biomass call for long-term considerations of the sustainability of and possible influences on the ecological, economic, cultural and social resource supply. The numerous goods and services provided by forests, such as habitats, biological diversity, recreational uses and other environmental functions in addition to the biomass and wood-based products, are broadly referred to as forest Ecosystem Services (ESs) (Constanza et al., 1997; Daily et al., 1997).

Excluding forest areas managed for the provision of specific ESs such as protection of water resources or erosion control (Krieger, 2001), the primary management objectives of a typical Scandinavian boreal forest are most often related to providing timber, habitats, recreational amenities (e.g., Kangas et al., 1992, 2008), and more recently, carbon storage or sequestration (Pukkala, 2016). These ESs can be categorized as in Table 1 following the classification of the Millennium Ecosystem Assessment (MEA, 2005). Even though an aggregate provisioning of several and parallel ESs is usually preferred over exclusive objectives related to single ESs (Hänninen et al., 2011), Table 1 illustrates the dimensions of the multiple criteria decision problem at hand: how to allocate a forest area to the production of various ESs, which differ in terms of rivalry and excludability (Wunder and Jellesmark Thorsen, 2014), require different forest management practices (Pukkala, 2016), and provide different benefits depending on the properties of the forest site and the objectives of its owner. When the preferences of the decision maker are known, rather generic tools can be applied to support the decision making based on the available data. Two broad categories of methods are presented in the literature (cf., Kangas et al., 2008): multiple criteria decision analysis (MCDA) for discrete and optimization for continuous problems, the applications of 
which are reviewed in a forestry context by Uhde et al. (2015) and Pukkala (2008), respectively, and by Langemeyer et al. (2016) regarding ES assessments in general.

\section{[ TABLE 1 AROUND HERE ]}

To integrate multiple ESs in forest management planning, the benefits provided by the different services must be numerically described, assessed in the same scale and modeled according to measurable forest attributes (Pukkala, 2008). Although estimating the benefits in terms of monetary values is common (Troy and Wilson, 2006; Nelson et al., 2009; Bottalico et al., 2016), it may also be criticized due to methodological heterogeneity that produces uncertainties in the obtained results (see, e.g., D'Amato et al., 2016). Alternative methods build upon the Multi-Attribute Utility Theory (MAUT), in which a utility (or priority or benefit) function is a mathematical transformation that associates a utility with each alternative so that all alternatives may be ranked (Cohon, 1978). Such functions are most often used to estimate the preferences of a decision maker (e.g., Keeney and Raiffa, 1976). However, by quantifying all alternative forest management objectives in terms of the utility functions, both the qualitative and quantitative objectives can be analytically evaluated and compared with respect to the impacts on the overall and objective-specific utility (Kangas, 1993; Pukkala and Kangas, 1993). Utility functions that use forest mensurational parameters as predictors have been formulated for forest planning situations including habitat (Kangas et al., 1993a; Kurttila et al., 2002), landscape (Kangas et al., 1993b; Pukkala et al., 1995), or multiple ES related objectives (Pukkala and Kurttila, 2005; Hurme et al., 2007; Schwenk et al., 2012). Deriving utility functions with spatial criteria based on Geographical Information Systems (GIS) has also been proposed for both the MCDA (Store and Kangas, 2001) and optimization (Packalén et al., 2011).

Information on the production possibilities may have been available for political decision making of very large areas (e.g., Backéus et al., 2005), but rarely in the operational (compartment) scale due to 
the high data acquisition costs involved in conventional field inventories. Recent developments of remote sensing (RS) technologies have brought spatially explicit estimates of various forest inventory, structure and habitat related parameters available for vast areas (Tomppo et al., 2008a,b, 2014; Maltamo et al., 2014; Barrett et al., 2016). For instance, generalizing field plot measurements using coarse- or medium-resolution RS and other numeric map data, referred to as Multi-Source National Forest Inventory (MS-NFI; Tomppo et al., 2008a) has been used to generate pixel-wise (Tuominen et al., 2010) or aggregated (Mäkelä et al., 2011) maps of biomass-related attributes, carbon storage (Akujärvi et al., 2016; Mononen et al., 2017), biological diversity (Lehtomäki et al., 2009, 2015; Räsänen et al., 2015), habitats (Vatka et al., 2014; Björklund et al., 2015) or berry yields (Kilpeläinen et al., 2016). Applying RS data to analyze multiple forest ESs, Frank et al. (2015) evaluated the biomass provisioning potential and tradeoffs for other ESs, when the land use of a region located in Germany was expected to change according to climate-adapted management scenarios. Sani et al. (2016) carried out a spatial MCDA based on multi-source data and expert knowledge to rank alternative land uses in a mountain forest in Iran. Matthies et al. (2016) assessed intra-service tradeoffs within the Payments for Ecosystem Services (PES) scheme based on the Finnish MS-NFI data. Schröter et al. (2014) examined tradeoffs between timber production and pooled biodiversity and other ES features using a pixel size of $500 \times 500 \mathrm{~m}^{2}$. Despite the successful examples of using RS-based inventory data for the assessment of multiple ESs, we are not aware of results that would allow formulating management prescriptions at the level of operational management units (e.g., forest compartments).

In summary, even though RS-based data often describe the ESs as indirect proxies (Andrew et al., 2014), such maps may enable to spatially identify areas which differ with respect to the supply of the ESs and thus require different forest management (cf., Pukkala 2016). Applying the RS-based proxies of the ESs in multi-objective forest management (e.g., Davis et al., 2001) of private forests produces specific, unsolved research questions, in addition to those generally present in integrating ESs in 
landscape planning (de Groot et al., 2010). In Europe, private forest owners hold 51\% of the total forest area (FOREST EUROPE, 2015), this percent increasing towards northern Europe (Finland, Norway, Sweden). The derived management plan should instruct the forest owner on which silvicultural treatments to perform on individual forest compartments, typically $1.5-2$ ha in size in Finland (Koivuniemi and Korhonen, 2006), to reach the overall objectives for the forest property. Applying existing models (Table 1 ) to the RS-based inventory data would allow wall-to-wall assessments of the provisioning potential of multiple ESs presented as a grid of pixels with a fraction-of-hectare scale, i.e., in a considerably more detailed resolution than the current operational compartments. This is expected to allow formulating management units that are more efficient in utilizing the production possibilities of the forest compared to conventional stands with fixed boundaries (Heinonen et al., 2007). In that case, essential questions are (i) to what degree do the alternative ESs overlap in the same area and (ii) what are the trade-offs for selecting one ES over another.

Our purpose was to perform a case study to provide an example of implementing decision analyses of multiple ESs using grid-based forest inventory data. Particular aims were (i) to analyze the degrees of overlap and spatial arrangements of the ESs prioritized to their most feasible locations; (ii) to explain the occurrences of sites with a potential to provide multiple ESs with respect to forest structure; and (iii) assess the degree of tradeoffs for an unconstrained optimal solution due to decisions to preserve a fraction of the landscape to the production of selected ESs based on the information obtained. The prioritization workflow and information sources are discussed based on these experiences.

\section{Material and methods}

\subsection{Study area}


The study area is located in the southern boreal forest zone (approximately $61.23^{\circ} \mathrm{N}, 25.11^{\circ} \mathrm{E}$; the map of the study area is presented as Figure A.1). The elevation is typically $125-145 \mathrm{~m}$ above sea level and mineral soils with gentle slopes prevail. The area of altogether $>7,500$ ha is state-owned and a part of the Natura-2000 network of the European Union. The landscape mosaic consists of forests, mires, lakes and brooks. The total forest area of approximately 6,350 ha varies from intensively managed to semi-natural and natural forests. Nature reserves cover almost 700 ha. Altogether $62 \%, 34 \%$ and $4 \%$ of the pixels in the MS-NFI data of the area (see Section 2.2.) are dominated by Norway spruce (Picea abies L. [H. Karst.]), Scots pine (Pinus sylvestris L.) and a group of deciduous trees, respectively. Although birches (Betula spp. L.) constitute the majority of the deciduous trees, species such as aspen (Populus tremula L.), alders (Alnus spp. P. Mill.), willows (Salix spp. L.), and rowan (Sorbus aucuparia L.) are common in mixed stands and below the dominant canopy. Using forest types as site fertility classes according to Cajander (1926), altogether $0.2 \%$ of the sites could be classified as Oxalis-Maianthemum (herb-rich), 26\% as Oxalis (rich mesic), 64\% as Myrtillus (mesic), $9 \%$ as Vaccinium (sub-xeric), and $0.8 \%$ as Calluna (xeric) type.

\subsection{Overview of the analyses}

Our analyses were based on spatially identifying the level of supply of the ESs and prioritizing the land use with respect to the ES with the highest supply. The models of Table 1 were applied to produce pixel-wise proxies of the ESs, assuming those to convey the information required for the analyses. In Table 1, cultural services differ from the others, as the aim was to aggregately proxy the most popular forest recreational activities in Finland (Sievänen and Neuvonen, 2011). Although picking berries could principally be thought as a provisioning service, it is categorized as a recreational forest activity since due to everyman's rights, berry picking does not provide a similar market value for the forest owner than wood-based biomass, but the management of the forests 
considerably differs between these services. Particularly, timber production is assumed to involve intensive management, which cannot be applied without restrictions unless losing recreational amenities. However, excluding clear-cutting, less intensive forestry may even improve these amenities and similar management practices may be applied with respect to both scenic values and berry yields (cf., Silvennoinen et al., 2002; Miina et al., 2016). Although the selection and division of the ESs (Table 1) may be further criticized, our analyses are expected to include the major ES categories, which need to be distinguished in land use planning with respect to forest management.

The actual workflow involved four discrete steps described in detail in the following sections:

- Obtaining the forest inventory data for the ES proxies (Section 2.3),

- Computing the ES proxies (Section 2.4),

- Converting the ES proxies to the same scale for the prioritization (Section 2.5),

- Analyses of the obtained priority layers (Section 2.6), divided to those focusing on

1. spatial overlaps between the individual ESs

2. provisioning potential of multiple ESs with respect to the forest structure, and

3. tradeoffs due to constraining a certain proportion of the pixels in the entire landscape for the production of a certain ES.

\subsection{Forest inventory data}

The required forest attributes were extracted from publicly available geospatial data. The MS-NFI data was the main source for all other attributes except the dominant height, which was derived using a model based on airborne laser scanning (ALS) data. The data were processed using the functions of ArcGIS, v. 10.3 (ESRI, 2014) and in-house scripts mainly based on the Geospatial Data Abstraction Library (GDAL Development Team, 2015). 
204

205

206

207

208

209

210

211

212

213

214

215

216

217

218

219

220

221

222

224

The MS-NFI data were downloaded from the file service of the Natural Resources Institute Finland (2016), in which the forest attribute estimates for the entire Finland are available as thematic raster maps. We extracted the layers depicting site fertility, growing stock volume and biomass components by tree species, total basal area and mean diameter and height corresponding to those of the (basal area weighted) median tree. As described by Tomppo and Halme (2004) and Tomppo et al. (2008a, 2014), the layers had been produced using a $k$-nearest neighbor ( $k$-NN) estimation method based on optimized neighbor and feature selection. The method used various satellite images from 2012-2014 and NFI field plot measurements from 2009-2013, which were updated to correspond the situation in mid-2013 using growth models. To increase the reliability of the data due to averaging the errors in the estimates, we re-scaled the original resolution of $16 \times 16 \mathrm{~m}^{2}$ to $48 \times 48$ $\mathrm{m}^{2}$ as the mean of 9 individual $16 \mathrm{~m} \times 16 \mathrm{~m}$ pixels (see discussion related to this choice in Section 4). All non-forested areas such as roads, lakes, settlements and agricultural lands were masked out from the analyses, retaining altogether 27,575 pixels of $48 \times 48 \mathrm{~m}^{2}$.

The ALS data were downloaded from the file server of the National Land Survey of Finland (2015). The data were acquired on May 13, 2012. Leica ALS50 scanner was operated from 2,200 m above ground level in a multipulse mode, using a scanning angle of $\pm 20^{\circ}$ and a ground footprint of approximately $50 \mathrm{~cm}$. These parameters yielded a nominal data density of 0.65 pulses $\mathrm{m}^{-2}$. The data provider had pre-classified the ground points of the data. We normalized the vegetation heights with respect to a triangulated irregular network (TIN) formed from the ground points, using LAStools, v. 151130 (Isenburg, 2015). The ALS data were tessellated to the $48 \times 48 \mathrm{~m}^{2}$ resolution corresponding to the MS-NFI data and pixel-wise estimates of the dominant tree height were computed using a model proposed by Kotivuori et al. (2016). Central characteristics of the MS-NFI and ALS data are presented in Table 2.

[ TABLE 2 AROUND HERE ] 


\subsubsection{Biodiversity}

234

To describe the aggregated amount of potential ecological features in a pixel, layers depicting the maturity and stocking of the forest in different species and sites were derived based on the data. The volume and mean diameter of the growing stock were assumed to be related to the pixel-specific conservation value via species-specific sigmoidal transformation functions based on expert knowledge (Lehtomäki et al., 2015). Applying the functions yielded the highest conservation values for mature, densely stocked forests with a high proportion of deciduous trees. To derive the layers, we followed the workflow termed as "Coarse with classes" (Lehtomäki et al., 2015) as closely as possible. The main exception was that we did not try to estimate the mean diameter of each species, which was not available in the data, but applied a single sigmoidal function according to the dominant species and mean diameter of a pixel.

An index layer determining the dominant tree species (pine, spruce, birch or other deciduous) was first generated by assigning the species with the highest proportion of growing stock volume as the dominant species of a pixel. For pixels with equal proportions of several species, the dominant species was determined as the species with the highest proportion in the neighborhood of $3 \times 3$ pixels. A species-specific conservation value function (Lehtomäki et al., 2015) was selected according to the dominant species, applied to the mean diameter and multiplied by the species-specific volume of the growing stock to obtain an indicator of the conservation value of a pixel. These layers were re-classified into five classes based on the site fertility. As a result, altogether 20 layers with different tree species $\times$ site fertility combinations were obtained. 


\subsubsection{Timber}

Soil expectation value (SEV), i.e., the present value ( $€ / h a)$ of the costs and revenues resulting from timber production when the management rotations are expected to continue in perpetuity, was used as the indicator of the pixel-wise timber production potential. The SEV was predicted using site fertility, growing stock and operational environment (temperature, interest rates and prices) related parameters as predictors in a model, which was fit based on average SEVs obtained from a very high number of simulated rotations, in which the stand treatments were optimized for timber production (Pukkala, 2005). All other predictors except the number of trees per hectare were readily available in the MS-NFI data, and its estimate was computed by dividing the total basal area by the mean diameter, i.e., assuming that the resulting number of average-sized trees existed in a pixel. The effective temperature sum was fixed to 1,300 degree days, but otherwise the SEVs were computed as averages of interest rates of $1-4 \%$ and combinations of saw-wood/pulpwood price (units in $€ / \mathrm{m}^{3}$ ) of $30 / 15,30 / 25,40 / 15,40 / 25,40 / 35,50 / 25$, and 50/35, which are the same combinations as employed in the simulations of the model data (Pukkala, 2005). The final SEV per pixel is thus an average value of altogether 28 interest rate and price combinations. For pixels with more than one species, the SEV was computed as a weighted average according to the proportions of the species according to the suggestion by Pukkala (2005).

\subsubsection{Carbon}

The carbon storage of the forest was estimated by multiplying the total biomass with a conversion factor. The total biomass was computed by summing the estimates of individual biomass components (living and dead branches, stem and bark, stump, roots, foliage). Because the carbon content of woody matter (roots, stem and branches) and leaves (needles) is reported as approximately $50 \%$ of their total biomass (Laiho and Laine, 1997; Thomas and Martin, 2012; IPCC, 
2003), the total carbon storage (tonnes/ha) of a pixel was determined by multiplying the estimated total biomass by 0.5 .

\subsubsection{Recreation}

Acknowledging that very different aspects likely constitute the recreational value of a forest for different people, we attempted to model a general suitability of the forest for recreation. Excluding activities that involved a sport pursuit or land ownership, berry picking and forest sightseeing were the most popular recreational nature attractions in Finland in 2010 (Sievänen and Neuvonen, 2011). Thus, our recreation layer is a composite of expert models for the suitability of a stand for bilberry (Vaccinium myrtillus L.) and cowberry (Vaccinium vitis-idea L.) picking (Ihalainen et al., 2002) and its visual amenity (Pukkala et al., 1988). The suitability of the pixels for each of these sub-activities was first predicted using the MS-NFI layers, the number of stems estimated as in Section 2.3.2., and the dominant height modeled from the ALS data as predictors of the respective models. The predictions were scaled between 0 and 1 and the final composite layer was obtained as a per-pixel maximum of the normalized values. Pixels with high suitability for one of the activities listed above thus obtained a high value in the resulting recreation layer.

\subsection{Scaling and prioritization of the ESs}

Although a number of alternative scaling approaches could be used, our analyses were based on the Zonation software, version 4.0 (Moilanen et al., 2014), due to its favorable features allowing analyses of information stored on single or multiple layers and built-in analysis and reporting tools. The Additive Benefit Function (ABF; Moilanen, 2007; Arponen et al., 2005) and Boundary Length Penalty (BLP; Moilanen and Wintle, 2007) modes of Zonation were used for non-spatial and spatial analyses, respectively, as detailed below. 
The ES proxies were scaled between 0 and 1 by iteratively removing the pixels that caused the least marginal loss in the (weighted) ES proxy. Starting from the full set of pixels $S$, the marginal loss $\delta$ is computed for pixel $i$ as (adapted from Arponen et al., 2005; Moilanen, 2007; Moilanen et al., 2014):

$$
\delta_{i}=w_{j} \sum_{j=1}^{J}\left[R_{j}(\{s\})-R_{j}(\{s-i\})\right]+p,
$$

where $R_{j}()$ is a function measuring the representation of ES layer $j$ in the set of remaining pixels $s$ and $s$ minus pixel $i ; s, i \in S ; w_{j}$ is the weight specified for ES layer $j$ and $p$ is the BLP term (see below). The pixel(s) with lowest $\delta$ are removed from the solution in each iteration and the priority value of the pixel removed as $n$ :th is obtained as $n / N$, where $N$ is the total number of pixels. The final prioritization maps were produced by removing 100 pixels at each iteration, as this accelerated the computations but did not affect the performance of the prioritization based on the initial tests.

With respect to forest management, it may be feasible to aim at large treatment units, i.e., to propose a joint management prescription for a group of pixels, even if the solution for one or few pixels differs from this proposition. To examine the effects of diverging from the non-spatial solution due to aggregating, the analyses were alternatively run by adding the marginal loss (Eq. 1) with a BLP term:

$$
p=\beta \times \Delta(B L / A),
$$

where $\beta$ is a user-defined parameter for the magnitude of the penalty and $\Delta(B L / A)$ is the change in boundary length-area-ratio of the solution due to removing pixel $i$ from the remaining set of pixels. If the removal of the pixel in question reduced the boundary length, $\Delta(B L / A)$ received a negative value and higher the value of $\beta$, the more the removal of such pixels was accelerated relative to their locally computed marginal loss. We ran the analyses using $\beta$ values of 0 (non-spatial analyses), 0.01 , $0.02,0.04$, and 0.06 (spatial analyses). 
333 All other ESs included in our analyses were composed of a single layer (i.e., $j=J=w_{j}=1.0$ in Eq. 1), except biodiversity, which included altogether 20 layers (see Section 2.3.1.). The biodiversity layers were weighted precisely according to the "Coarse with classes" workflow (see Appendix S1 of Lehtomäki et al., 2015). According to these weights, simultaneous occurrences of biodiversity features increase the conservation value of the pixel depending on the site fertility and dominant tree species. Each individual ES was prioritized in separate Zonation runs, yielding four maps with priority values between 0 and 1 according to the range of values in the initial layers. All other ESs were included in the runs with weights of 0.0 , which did not influence the priority ranking but allowed calculating some reporting features (see Section 2.5.). However, we also included all the ESs in a single run to test balancing the allocation of the ESs in the entire landscape by considering their joint occurrences during the prioritization (cf., Moilanen et al. 2011). In this analysis, the weights of the ESs were determined assuming that timber production was particularly harmful for the provisioning of all other ESs. The SEV layer thus obtained a weight of -3 , and all other ESs a weight of 1 , totaling to 0 . This analysis resulted in a priority map, in which the highest values indicated suitability for the production of all other ESs and lowest values for timber production. Otherwise, the priority values were interpreted according to MAUT, i.e., the ES with the highest priority value was selected as the most suitable ES for the specific pixel.

\subsection{Analyses}

The spatial distribution and overlaps between the priority rankings were examined based on map and performance analyses. Among the reporting tools of Zonation (Moilanen et al., 2014), we used the landscape solution comparison and performance curves to determine the degree of overlap between two priority ranking maps. The performance curves, drawn during the pixel removal, show the fraction of the ESs represented in the landscape when the given proportion of pixels is removed from the solution and the removal is ordered according to the ES considered in the prioritization. We 
359

360

361

362

363

364

365

366

367

368

369

370

371

372

373

374

375

376

377

378

379

380

381

were especially interested in whether a given percentage of the most important pixels of the different ESs overlapped and examined this degree based on various map analyses. The percentage of overlapping pixels and a Jaccard's similarity index (cf., Arponen et al., 2012), determined by dividing the number of pixels shared between solutions $S$ and $S_{c}$ by the total number of pixels in both the solutions $\left(\frac{S \cap S_{c}}{S \cup S_{c}}\right)$, were used as the evaluation criteria. The Jaccard index was particularly used for comparing the overlaps between the local and BLP-averaged solutions.

In addition to the distribution of the individual ESs, we were interested in whether the ESs categorized in Table 1 occurred in same locations and whether the forest structure explained these occurrences. For this purpose, we computed the total Ecosystem Service Potential (ESP) as:

$$
E S P=\left(\sum_{k}^{K} p_{k, l}\right) / K,
$$

where $K$ was the total number of ESs (here 4 ) and $p_{k, l}$ the priority value of the $k$ :th ES in pixel $I$. The ESP index thus obtained values between 0 and 1, 1 indicating that all ESs had high priorities within the pixel. We modeled the relationship between the ESP index and forest structural variables as a logistic function:

$$
\widehat{E S P}=\frac{1}{1+e^{a \times(b-v)}}
$$

where $v$ was the forest structural variable considered as the predictor and $a$ and $b$ were model parameters estimated separately according to different dominant species and site types using $R$ ( $R$ Core Team, 2016). We also split the continuous ESP to four classes indicating low to high occurrences of the multiple ESs and analyzed the variation of forest structural attributes in these classes. The classes were obtained according to the thresholds $0.25>E S P, 0.5>E S P \geq 0.25$, $0.75>E S P \geq 0.5$, and $E S P \geq 0.75$ and are denoted to in the following text as $\mathrm{ESP}_{1}, \mathrm{ESP}_{2}, \mathrm{ESP}_{3}$, and $\mathrm{ESP}_{4}$, respectively. 
Finally, we assessed the tradeoffs for optimal decisions due to allocating the provision of the ESs according to the priority rankings. Among the ESs considered, only SEV and carbon produced meaningful information when used as target functions in optimization, i.e., minimized or maximized.

On the other hand, requirements to retain a certain proportion of the forest for biodiversity or recreation could be seen to constraint the optimal solution. It could particularly be assumed that no SEV from timber production could be obtained when a pixel was assigned for biodiversity or recreation, whereas the full value of the carbon storage was retained as if the pixel was managed for this ES. Following this logic, we first computed a tradeoff curve indicating the Pareto optimal production frontier by maximizing the SEV with the amount of carbon storage fixed to $1,10,20, \ldots$, $90,99 \%$ of its total value. The optimality losses due to assigning sites with the highest priority for biodiversity or recreation to carbon storage, regardless of their timber production potential, were compared with the optimized curve. Following the recommendations of Strimas-Mackey (2016) based on a comparison of alternative integer linear programming solvers, the optimization was implemented using R package glpkAPI (Gelius-Dietrich, 2015).

\section{Results}

The priority ranking maps obtained for the individual ESs are presented as Appendix B, while Figure 1 shows the result of selecting the ES with the highest priority per pixel according to MAUT. It can be noted that both the selection (Figure 1) and the most or least important areas for the representation of the ESs in the landscape (Appendix B) formed aggregated, stand-like patterns even though the neighborhoods of the individual pixels were not considered. The landscape was further smoothed by penalizing the marginal loss function (Eq. 1) using the BLP (Figure 2). Using a BLP value of 0.01, in particular, the Jaccard index measuring the spatial overlap of similar pixels remained $>0.8$ for all the ESs until the priority value level of 0.7 (Figure 2, above). Beyond that level, the BLP parameter altered the most important sites of all the ESs considered, having least effects on the priority ranking 
of biodiversity (Figure 2, above). As expected, increasing the value of the BLP parameter reduced the spatial overlap (Figure 2, below). Due to the regular spatial arrangement of the priorities without the $B L P$, however, we only present results computed with BLP=0.

\section{[ FIGURES 1 AND 2 AROUND HERE ]}

When the management of the pixels was decided according to the ESs with the highest priority as in Figure 1, altogether $25.6 \%, 20.1 \%, 29.3 \%$, and $25.0 \%$ of the pixels were allocated for biodiversity, carbon storage, recreation, and timber production, respectively. The difference in the priority values of the highest two ESs was $\leq 0.1,>0.1$ but $\leq 0.2$, and $>0.2$ in altogether $58.7 \%, 22.8 \%$, and $18.5 \%$ of the pixels. The aforementioned categories had an average \pm standard deviation of the highest priority values of $0.66 \pm 0.28,0.71 \pm 0.21$, and $0.76 \pm 0.18$, respectively. The decision on the most suitable ES may thus be considered uncertain for at least half of the pixels, but the uncertainty was more emphasized on pixels with lower priorities, on average, and less on the most important sites for the ESs considered.

Figure 3 illustrates the decision to preserve the most important fraction of the landscape to the management of a specific ES, assuming that values of all ESs in the sites not selected were lost. Particularly, the $y$-axis of the diagram gives the fraction of the ES remaining, when the fraction of least important pixels indicated by the $\mathrm{x}$-axis was removed from the entire landscape. A diagonal line from $x=0$ and $y=1$ to $x=1$ and $y=0$ would indicate an equal reduction of the ES values with the land area (or a random cell removal), whereas above or below diagonal lines indicate a slower or faster reduction, respectively. Figure 3 indicates that the ES values always reduced slower than the land area, when the pixels were removed according to the priority ranking of the selected ES, whereas the effects on the other ESs vary. Especially, a considerable proportion of biodiversity was lost, when the pixel removal was prioritized according to the other ESs, and its value was preserved only by 
considering biodiversity in the prioritization of the pixel removal. Prioritizing the pixel removal according to recreation (Figure 3d) produces an interesting case for biodiversity, as its performance curve first sharply reduces, then stabilizes and finally results in the upper diagonal of the graph. According to the models (Table 1), old and mature stands produce high recreational values, but only those on fertile sites are most important for biodiversity. Thus, the progress of the prioritization from old and mature spruce forests to pine stands on poorer sites provides a credible explanation for the shape of the performance curves in Figure 3(d). Carbon storage and timber production performed similarly among themselves and had less benefit compared to biodiversity or recreation from being the objective of the prioritization. Balancing the allocation of the ESs in a single run especially retained a similar shape of the biodiversity curve as if it was the objective of the prioritization (Figure 4).

\section{[ FIGURES 3 AND 4 AROUND HERE ]}

The degree of overlap of the most important $10 \%$ and $30 \%$ of the pixels of each ES is presented in Table 3, while Figure 5 depicts the spatial distribution of these overlaps for the most important 30\% of the pixels. Of the $10 \%$ and $30 \%$ most important sites for biodiversity, altogether $16.6-30.8 \%$ and 46.8-50.1\%, respectively, overlapped with similarly prioritized sites of the other ESs (Table 3). The respective figures were at the same level for recreation (25.5-30.8\% and $45.5-52.5 \%)$, but higher for carbon storage and timber production. Especially, the $10 \%$ and $30 \%$ of the most important sites for carbon storage and timber production had a mutual overlap of $66.5 \%$ and $78.0 \%$, respectively. When the services that formed the recreation layer, i.e., berry yields and visual amenity, were prioritized separately, the individual services had a lower or an equal level of overlaps with biodiversity than the composite layer. The sites suited for bilberry picking had a higher overlap with sites suited for carbon storage and timber production, while the most important sites for cowberry picking had practically no overlaps with any other ESs except a low degree of coincidences with those modeled 
461

462

463

464

465

466

467

468

469

470

471

472

473

474

475

476

477

478

479

480

481

482

483

484

485

as visually pleasant. Figure 5 adds the information of Table 3 in that the sites important for biodiversity and recreation, which had no overlaps with other services, were not scattered but often formed aggregates of several pixels. The most important sites for carbon storage and timber production were especially overlapped in both the eastern and western parts of the study area (Figure 5).

\section{[ TABLE 3 AND FIGURE 5 AROUND HERE ]}

The overlaps of the multiple ESs in the landscape (Figure 5) could be explained to a large degree by relating the ESP index with forest structure. Especially, the condensations of multiple ESs could be clearly distinguished in terms of size-related forest attributes (Figure 6a-d) as being emphasized in sparsely populated old forests with large average tree size. The median values of mean age, mean diameter, dominant height, and number of trees were 78.5 years, $27.3 \mathrm{~cm}, 29.2 \mathrm{~m}$, and $475 \mathrm{ha}^{-1}$ in the $\mathrm{ESP}_{4}$ category, whereas the respective figures in the $\mathrm{ESP}_{1}$ category were 36.8 years, $13.0 \mathrm{~cm}, 9.5$ $\mathrm{m}$, and $1057 \mathrm{ha}^{-1}$. Also, the $\mathrm{ESP}_{4}$ category often had less occurrences of separate species (Figure 6e), a higher proportion of dominant species (Figure 6f; a median value of $73.3 \%$ in the $\mathrm{ESP}_{4}$ category vs. 46.0\% in $\mathrm{ESP}_{1}$ ) and a stronger dominance of the coniferous tree species (Figure $6 \mathrm{~g}-\mathrm{h}$ ). Figure 7 further depicts the joint effects of stand maturity, species and site fertility to the ESP. The highest values (ESP $\geq 0.9$ ) were reached in spruce and pine dominated stands on herb-rich to mesic sites with the total volume of the growing stock $\geq$ approximately $300 \mathrm{~m}^{3} /$ ha. Occurrences of up to $2-3$ ESs $(0.75>E S P \geq 0.25)$ were met in deciduous forests, less stocked coniferous stands or those growing on poorer sites (Figure 7).

[ FIGURES 6 AND 7 AROUND HERE ] 
Allocating the landscape to the management of the multiple ESs according to the local priorities of the ESs always resulted in sub-optimal choices compared to the optimized production of carbon and timber. Figure 8 illustrates the degree of tradeoffs due to constraining the production on a given percent of the landscape and particularly an increasing proportion of tradeoffs for optimized timber production according to a higher fraction of landscape allocated for alternative ESs based on the priority maps. A numerical example produces more information on the magnitude of the tradeoffs (below, sites with priority $\geq 0.9$ are considered most important for biodiversity or recreation):

- $90 \%$ of the landscape for timber production: When the remaining $10 \%$ was selected from the Pareto optimal production frontier, altogether $76.6 \%$ or $80.2 \%$ of the most important sites for biodiversity or recreation, respectively, were lost. When the same $10 \%$ fraction was selected based on the priority maps, the SEV was $97.4 \%$ or $96.6 \%$, respectively, of the optimized solution.

- $10 \%$ of the landscape for timber production: When the remaining $90 \%$ was selected from the Pareto optimal production frontier, altogether $7.7 \%$ or $10.4 \%$ of the most important sites for biodiversity or recreation, respectively, were lost. However, selecting the $10 \%$ timber production sites as those least important for biodiversity or recreation resulted in an SEV of only $54.5 \%$ or $53.6 \%$, respectively, of the optimized solution.

Allocating the land for the ESs with the highest priority per pixel as in Figure 1 resulted in one of the least effective solutions (Figure 8). Although the example suggests that the joint production of the ESs cannot be effectively decided based on the local priorities, it is noted that weighting the opposing ESs properly might provide a compromise between the use of the priority maps and global optimization. For instance, using the balanced weighting (cf., Section 2.4.; Figure 4) to allocate a half of the landscape for timber production and the other half for the other ESs, only altogether $4.7 \%$ or $7.8 \%$ of the most important sites for biodiversity or recreation, respectively, were lost while 
511 providing as much as $89.8 \%$ of the SEV compared to the solution, in which the timber production was optimized retaining $50 \%$ of the most important sites for carbon.

[ FIGURE 8 AROUND HERE ]

515

\section{Discussion}

517

The presented approach integrated RS-based forest inventory data and expert models for spatially explicit decision analyses of the ESs listed in Table 1. Our analyses were, to a high degree, based on using indirect proxies, which were assumed to spatially identify the areas with a high supply of the ESs. The use of the proxies is criticized in the literature (Eigenbrod et al., 2010). Especially, a number of other ecosystem services may benefit from or depend on biodiversity-related characteristics (Harrison et al., 2014), the related linkages and criteria being currently incompletely understood (de Groot et al., 2016). The use of the indirect proxies may be seen as a weakness of our approach, whereas the MAUT-based valuation, which allowed a direct use of these proxies without the requirement for conversion to monetary values, is expected to reduce the uncertainties between the decisions. Unlike in the study of Sani et al. (2016), we obtained this information without expert (or stakeholder) involvement using existing models. Whether the preferences of the stakeholders toward the ESs were known, incorporating them in the analyses would have been straightforward based on the techniques reviewed by Uhde et al. (2015) and Pukkala et al. (2014). The preferential

531 information would further allow solving conflicts between the ESs with highest overlaps such as 532 using the forest for timber production or carbon storage. As an alternative to applying models of 533 Table 1 and re-scaling the values, the total ES potential (cf., Figure 6) could readily be modeled as a 534 sigmoidal function, which could principally be operated at the level of individual trees similar to the 535 functions for determining the conservational or economic potential as in Lehtomäki et al. (2015) and Vauhkonen and Pukkala (2016), respectively. 
According to our results, the assessment and prioritization of the ESs produced by a typical

Scandinavian boreal forest (Table 1) can be implemented based on existing models and publicly available forest inventory data. However, our results also suggest that by roughly preserving a certain percentage of the sites with highest priority from commercial forest management may not be an appropriate strategy with respect to a joint production of multiple ESs. According to the tradeoff analysis (Figure 7), prioritizing ESs based only on local considerations using the priority maps may lead to high levels of tradeoffs without guaranteeing adequate levels of potential global criteria such as timber production for the entire planning area. Rather, Figure 7 should be interpreted as the interval of ES production levels that are possible, from which the most preferred one(s) according to the decision makers' preferences could be determined using techniques such as goal programming or penalty functions (Pukkala, 2008). Nevertheless, the workflow described in this paper produces potentially valuable information on the overlaps and tradeoffs for these processes.

To obtain prioritized ES maps, we followed a similar workflow that was earlier used to plan nature conservation (Lehtomäki et al., 2009, 2015) and alternative land uses (Moilanen et al., 2011), when maintaining high conservation value was the main criterion for the land use prioritization. The biodiversity prioritization maps are assumed to correspond those obtained in another region in Finland (Lehtomäki et al., 2015), because the same workflow was replicated as closely as possible. When the production potential of the alternative ESs was considered, altogether $17-49 \%$ of the most important sites for managing biodiversity were found to overlap with sites evaluated as equally important for the provisioning of alternative forest ESs. However, the overlaps between biodiversity and other ESs were lower compared to recreational use (overlaps of $26-53 \%$ with other ESs) and especially timber production and carbon storage (67-78\%). In an earlier study, Moilanen et al.

561 (2011) found a considerably lower degree of overlaps between alternative ecosystem services, when biodiversity conservation, carbon storage, agricultural value and urban development were 
563

564

565

566

567

568

569

570

571

572

573

574

575

576

577

578

579

580

581

582

583

584

585

586

587

prioritized in Great Britain. Yet, higher overlaps could be expected when focusing specifically on alternative forest ESs. In this sense, our results can be compared to Triviño et al. (2015), who considered only timber and carbon, but observed a similar level of overlaps between these ESs in mature and spruce dominated forest stands.

Our results are based on a landscape of altogether 7,500 ha. The values in the priority ranking maps vary between 0 and 1 according to the range of the ES proxies (Table 1) within this area, i.e., the same range of priority values is obtained even if the value of a certain ES is not very high compared to other areas. Although this is in line with our objective to produce instructions that can be implemented operationally for improving the management of the given forest property, it should be taken into account in comparisons with other studies. For instance, our results are at first glance in conflict with those obtained by Gamfeldt et al. (2013), who proposed the number of species as the main driver of occurrences of multiple ESs following an analysis carried out in Sweden. However, their results were based on data from an area of $400,000 \mathrm{~km}^{2}$, along which the forest vegetation changes from tundra-like to boreo-nemoral. Most likely, both the increased number of species and values of the ES proxies were related to the change in the vegetation zone. When focusing on an operational management planning scale, in which the vegetation zone is fixed, our results suggest that the total ES potential depends jointly on species, site fertility, and maturity as indicated in Figures 5 and 6 . Our analyses were carried out in an area belonging to the Natura-2000 network and expected to be rich in terms of the provisioning potential of all the ESs considered. However, as the importance of the ESs, their relationships with the forest structure, and balance between the demand and supply of the ESs (cf., García-Nieto et al., 2013) vary, our conclusions should not be generalized to cover, e.g., areas managed more intensively for the provision of a specific ES such as timber. 
588

589

590

591

592

593

594

595

596

597

598

599

600

601

602

603

604

605

606

607

608

609

610

611

612

613

Although we believe that the analysis described above illustrates the maximum tradeoffs for single vs. multiple ESs, we acknowledge that a high degree of simplification is included in the analysis.

Especially, the production constraints to preserve a site for biodiversity or recreation were assumed to prevent timber production but maintain the full carbon storage, which may not be true in practical forestry. Instead, the management rotations of recreational sites in particular may involve thinning-type of cuttings that provide SEV and even improve the visual amenity (Silvennoinen et al., 2002) or berry yields (Miina et al., 2016). Further, whether one had been interested in carbon sequestration in addition or instead of carbon storage (cf., Triviño et al., 2015), the development of models for the carbon pools of soil organic matter (e.g., mortality of trees, litter production, residuals of harvested trees and decomposition of organic materials) and life cycles of the wood products (e.g., harvested timber assortments and releases of harvesting, transporting and manufacturing) would have been needed (Pukkala, 2014). However, effects of various silvicultural systems to the production potential of the ESs can be derived from the study of Pukkala (2016), while Triviño et al. (2015) and Frank et al. (2015) provide analyses that involve simulations of future management rotations to study landscape or regional level potential of biomass and alternative ESs.

It is a recognized problem that the ES maps produced vary depending on the mapping technique (Schulp et al., 2014; Räsänen et al., 2015). Also in our analyses, the uncertainties involved in the data are, to a high degree, ignored. In the absence of field validation data, it is assumed that all inventory and model errors compensate each other and do not accumulate in the ES proxies, which is unlikely realistic. However, by testing the corresponding analyses in the original $16 \times 16 \mathrm{~m}^{2}$ resolution, we observed that the models of Table 1 produced unrealistic values for a number of pixels which then propagated to the ES priority estimates. By aggregating the data to the $48 \times 48 \mathrm{~m}^{2}$ resolution, no similar tendencies were observed and errors in the initial forest attribute estimates were likely reduced due to averaging. Although both the original (Kilpeläinen et al., 2016) and aggregated (Arponen et al., 2012; Lehtomäki et al., 2015) resolutions have been tested, based on the 
experiences described above, we recommend using only aggregated estimates. Nevertheless, the accuracy of the model estimates should also be verified with calibration data.

616

617 Overall, a compromise needs to be made between data acquisition costs and the uncertainty in the estimates. Our results are based on assessing the ESs based on publicly available forest data, which is highly feasible from the practical point of view. Whether resources for collecting calibration data for the purposes discussed above existed, the uncertainty of the models could be estimated and incorporated in the decision making. Since some of the forest attributes included in the existing models are difficult to observe based on RS, better results would likely be obtained by directly using the RS-based features to model the suitability of the forest for the ESs as determined in the field. Particularly, three-dimensional (3D) RS data have earlier been found to provide better estimates of biomass-related attributes (Kankare et al., 2015) and vegetation structure indices directly related to forest ecological attributes (see, Maltamo et al., 2014). Formulating suitability models for the ESs based on the 3D RS vegetation indices, as already proposed by Andrew et al. (2014) and Corona (2016), is among our future interests.

629

\section{Conclusions}

631

The applied workflow produced a realistic, spatially explicit description of the production possibilities of multiple ESs in the landscape tessellated to a resolution of $48 \times 48 \mathrm{~m}^{2}$. The priorities of the ESs formed aggregated, stand-like spatial patterns, even though the neighborhoods of the individual pixels were not considered in the prioritization. According to the models (Table 1), the maturity and stocking increased the joint potential of the ESs. Overlaps were found especially between timber production and carbon storage, which did not set weight for species composition and site fertility similar to recreation and especially biodiversity. Higher priorities of biodiversity were observed in richer fertility types and deciduous forests, while poorer and pine-dominated 
640 forests were preferred for recreational use. Information for identifying the overlapping and non-

641 overlapping sites was obtained without expert involvement, but based on models existing in the

642 literature. Applying the models on publicly available, spatially explicit data produced a feasible

643 priority mapping of the ESs in the landscape, which is somewhat useful information even if the

644 stakeholders' preferences are unknown.

645

646 Acknowledgements

647 This study was financially supported by the Research Funds of the University of Helsinki.

648

649 Supplementary data

650 We provide the layers described in Section 2.4. and setup files for Zonation, version 4.0., used in the 651 prioritization analyses of Section 2.5. as Supplementary Data. The contents of the package are 652 explained in the README.txt file located in the package. 
Akujärvi, A., Lehtonen, A., Liski, J., 2016. Ecosystem services of boreal forests-Carbon budget mapping at high resolution. J. Env. Manage. 181, 498-514.

658

Andrew, M.E., Wulder, M.A., Nelson, T.A., 2014. Potential contributions of remote sensing to ecosystem service assessments. Progr. Phys. Geogr. 38, 328-353.

Arponen, A., Heikkinen, R., Thomas, C.D., Moilanen, A., 2005. The value of biodiversity in reserve selection: representation, species weighting and benefit functions. Conserv. Biol. 19, 2009-

662 2014

Arponen, A., Lehtomäki, J., Leppänen, J., Tomppo, E., Moilanen, A., 2012. Effects of connectivity and spatial resolution of analyses on conservation prioritization across large extents. Conserv. Biol. 26, 294-304.

Backéus, S., Wikström, P., Lämås, T., 2005. A model for regional analysis of carbon sequestration and timber production. For. Ecol. Manage. 216, 28-40.

Barredo, J.I., et al., 2015. Mapping and assessment of forest ecosystems and their services Applications and guidance for decision making in the framework of MAES. Report EUR 27751 EN, Joint Research Centre, European Union, 78 p. doi: 10.2788/720519 review of the operational use of remotely sensed data by national forest inventories. Remote Sens. Environ. 174, 279-289.

Björklund, H., Valkama, J., Tomppo, E., Laaksonen, T., 2015. Habitat effects on the breeding performance of three forest-dwelling hawks. PloS ONE, 10(9), e0137877, doi: 10.1371/journal.pone.0137877 
Bottalico, F., Pesola, L., Vizzarri, M., Antonello, L., Barbati, A., Chirici, G., Corona, P., Cullotta, S., Garfi, V., Giannico, V., Lafortezza, R., Lombardi, F., Marchetti, M., Nocentini, S., Riccioli, F., Travaglini, D., Sallustio, L., 2016. Modeling the influence of alternative forest management scenarios on wood production and carbon storage: A case study in the Mediterranean region. Env. Res. 144, 72-87.

Cajander, A.K., 1926. The theory of forest types. Acta For. Fenn. 29, 1-108.

Cohon, J.L., 1978. Multiobjective programming and planning. Mathematics in Science and Engineering 140. Academic Press, New York.

Corona, P., 2016. Consolidating new paradigms in large-scale monitoring and assessment of forest ecosystems. Env. Res. 144, 8-14.

Costanza, R., d'Arge, R., de Groot, R., Farber, S., Grasso, M., Hannon, B., Limburg, K., Naeem, S., O’Neill, R.V., Paruelo, J., Raskin, R.G., Sutton, P., van den Belt, M., 1997. The value of the world's ecosystem services and natural capital. Nature 387: 253-60.

Daily, G.C., Alexander, S., Ehrlich, P.R., Goulder, L., Lubchenco, J., Matson, P.A., Mooney, H.A., Postel, S., Schneider, S.H., Tilman, D., Woodwell, G.M., 1997. Ecosystem services: Benefits supplied to human societies by natural ecosystems. Issues in Ecology 2: 1-16.

Davis, L.S., Johnson, K.N., Bettinger, P.S., Howard, T.E., 2001. Forest management - to sustain ecological, economic and social values. 4th ed. McGraw-Hill, New York.

D'Amato, D., Rekola, M., Li, N., Toppinen, A., 2016. Monetary valuation of forest ecosystem services in China: A literature review and identification of future research needs. Ecol. Econ. 121, 7584.

De Groot, R.S., Alkemade, R., Braat, L., Hein, L., Willemen, L., 2010. Challenges in integrating the concept of ecosystem services and values in landscape planning, management and decision making. Ecol. Compl. 7, 260-272. 
701

702

703

704

705

706

707

708

709

710

711

712

713

714

715

716

717

718

719

720

721

722

723

De Groot, R., Jax, K., Harrison, P., 2016. Link between Biodiversity and Ecosystem Services, in: Potschin, M., Jax, K. (Eds.), OpenNESS Ecosystem Services Reference Book. EC FP7 Grant Agreement no. 308428. http://www.openness-project.eu/library/reference-book/sp-linkbetween-biodiversity-and-ecosystem-services (accessed 28.11.16).

Eigenbrod, F., Armsworth, P.R., Anderson, B.J., Heinemeyer, A., Gillings, S., Roy, D.B., Thomas, C.D., Gaston, K.J., 2010. The impact of proxy-based methods on mapping the distribution of ecosystem services. J. Appl. Ecol. 47, 377-385.

ESRI, 2014. ArcGIS Desktop, version 10.3. Environmental Systems Research Institute, Redlands, CA. http://www.esri.com/software/arcgis (accessed 04.02.16).

FOREST EUROPE, 2015. State of Europe's Forests 2015. Ministerial Conference on the Protection of Forests in Europe, FOREST EUROPE Liaison Unit, Madrid, Spain. http://foresteurope.org/stateeuropes-forests-2015-report/ (accessed 28.11.16).

Frank, S., Fürst, C., Pietzsch, F., 2015. Cross-sectoral resource management: How forest management alternatives affect the provision of biomass and other ecosystem services. Forests 6, 533-560.

Gamfeldt, L., Snäll, T., Bagchi, R., Jonsson, M., Gustafsson, L., Kjellander, P., Ruiz-Jaen, M.C., Fröberg, M., Stendahl, J., Philipson, C.D., Mikusiński, G., Andersson, E., Westerlund, B., Andrén, H., Moberg, F., Moen, J., Bengtsson, J., 2013. Higher levels of multiple ecosystem services are found in forests with more tree species. Nat. Comm. 4, article number 1340, 1-8.

García-Nieto, A.P., García-Llorente, M., Iniesta-Arandia, I., Martín-López, B., 2013. Mapping forest ecosystem services: from providing units to beneficiaries. Ecosystem Serv. 4, 126-138.

GDAL Development Team, 2015. GDAL - Geospatial Data Abstraction Library, version 1.11.3. http://www.gdal.org (accessed 04.02.16).

Gelius-Dietrich, G., 2015. glpkAPI: R interface to C API of GLPK. R package version 1.3.0. https://CRAN.R-project.org/package=glpkAPI (accessed 28.11.16).

Hannerz, M., Nohrstedt, H.-Ö., Roos, A., 2014. Research for a bio-based economy in the forest sector - a Nordic example. Scand. J. For. Res. 29, 299-300. 
Harrison, P.A., Berry, P.M., Simpson, G., Haslett, J.R., Blicharska, M., Bucur, M., Dunford, R., Egoh, B., Garcia-Llorente, M., Geamănă, N., Geertsema, W., Lommelen, E., Meiresonne, L., Turkelboom, F., 2014. Linkages between biodiversity attributes and ecosystem services: A systematic review. Ecosystem Serv. 9, 191-203.

Heinonen, T., Kurttila, M., Pukkala, T., 2007. Possibilities to aggregate raster cells through spatial optimization in forest planning. Silva Fenn. 41, 89-103.

Hurme, E., Kurttila, M., Mönkkönen, M., Heinonen, T., Pukkala, T., 2007. Maintenance of flying squirrel habitat and timber harvest: a site-specific spatial model in forest planning calculations. Landscape Ecol. 22, 243-256.

Ihalainen, M., Alho, J., Kolehmainen, O., Pukkala, T., 2002. Expert models for bilberry and cowberry yields in Finnish forests. For. Ecol. Manage. 157, 15-22.

IPCC, 2003. Good practice guidance for Land Use, Land-Use Change and Forestry. National Greenhouse Gas Inventories Programme, The Intergovernmental Panel on Climate Change (IPCC), Japan, ISBN 4-88788-003-0.

Isenburg, M., 2015. LAStools - Efficient tools for LiDAR processing, version 151130. Rapidlasso GmbH, Germany. http://lastools.org (accessed 04.02.16).

Kangas, A., Kangas, J., Kurttila, M., 2008. Decision support for forest management. Managing Forest Ecosystems 16, Springer, Dordrecht.

Kangas, J., 1993. A multi-attribute preference model for evaluating the reforestation chain alternatives of a forest stand. For. Ecol. Manage. 59, 271-288.

Kangas, J., Matero, J., Pukkala, T., 1992. Analyyttisen hierarkiaprosessin käyttö metsien monikäytön suunnittelussa - tapaustutkimus (in Finnish for "Using the Analytic Hierarchy Process in planning of multiple-use forestry - A case study"). Finnish Forest Research Institute, Research Notes, 412. 
Kangas, J., Karsikko, J., Laasonen, L., Pukkala, T., 1993a. A method for estimating the suitability function of wildlife habitat for forest planning on the basis of expertise. Silva Fenn. 27, 259268.

Kangas, J., Laasonen, L., Pukkala, T., 1993b. A method for estimating forest landowner's landscape preferences. Scand. J. For. Res. 8, 408-417.

Kankare, V., Vauhkonen, J., Holopainen, M., Vastaranta, M., Hyyppä, J., Hyyppä, H., Alho, P., 2015. Sparse density, leaf-off airborne laser scanning data in aboveground biomass component prediction. Forests 6, 1839-1857.

Keeney, R.L., Raiffa, H., 1976. Decisions with multiple objectives: Preferences and value tradeoffs. John Wiley and Sons, New York.

Kilpeläinen, H., Miina, J., Store, R., Salo, K., Kurttila, M., 2016. Evaluation of bilberry and cowberry yield models by comparing model predictions with field measurements from North Karelia, Finland. For. Ecol. Manage. 363, 120-129.

Koivuniemi, J., Korhonen, K.T., 2006. Inventory by compartments, in: Kangas, A., Maltamo, M. (Eds.), Forest Inventory: Methodology and Applications. Managing Forest Ecosystems 10, Springer, Dordrecht, pp. 271-278.

Kotivuori, E., Korhonen, L., Packalen, P., 2016. Nationwide airborne laser scanning based models for volume, biomass and dominant height in Finland. Silva Fenn. 50, article id 1567. doi: $10.14214 /$ sf.1567

Krieger, D.J., 2001. The economic value of forest ecosystem services: a review. The Wilderness Society, Washington DC. http://www.truevaluemetrics.org/DBpdfs/EcoSystem/TheWilderness-Society-Ecosystem-Services-Value.pdf (accessed 05.08.16).

Hänninen, H., Karppinen H., Leppänen J., 2011. Suomalainen metsänomistaja 2010 (in Finnish for "Finnish Forest Owner 2010"). Working Papers of the Finnish Forest Research Institute 208, ISBN 978-951-40-2317-0. 94 p. http://www.metla.fi/julkaisut/workingpapers/2011/mwp208.htm (accessed 05.08.16). 
Kurttila, M., Pukkala, T., Loikkanen, J., 2002. The performance of alternative spatial objective types in forest planning calculations: a case for flying squirrel and moose. For. Ecol. Manage. 166, 245260.

Laiho, R., Laine, J., 1997. Tree stand biomass and carbon content in an age sequence of drained pine mires in southern Finland. For. Ecol. Manage. 93, 161-169.

Langemeyer, J., Haase, D., Elmqvist, T., Scheuer, S., Gómez-Baggethun, E., 2016. Bridging the gap between ecosystem service assessments and landuse planning through Multi-Criteria Decision Analysis (MCDA). Env. Sci. Pol. 62, 45-56.

Lehtomäki, J., Tomppo, E., Kuokkanen, P., Hanski, I., Moilanen, A., 2009. Applying spatial conservation prioritization software and high-resolution GIS data to a national-scale study in forest conservation. For. Ecol. Manage. 258, 2439-2449.

Lehtomäki, J., Tuominen S., Toivonen, T., Leinonen A., 2015. What data to use for forest conservation planning? A comparison of coarse open and detailed proprietary forest inventory data in Finland. PloS ONE 10(8), e0135926, doi: 10.1371/journal.pone.0135926

Mäkelä, H., Hirvelä, H., Nuutinen, T., Kärkkäinen, L., 2011. Estimating forest data for analyses of forest production and utilization possibilities at local level by means of multi-source national forest inventory. For. Ecol. Manage. 262, 1345-1359.

Maltamo, M., Næsset, E., Vauhkonen, J. (Eds.), 2014. Forestry applications of airborne laser scanning - concepts and case studies. Managing Forest Ecosystems 27, Springer, Dordrecht.

Matthies, B.D., Kalliokoski, T., Eyvindson, K., Honkela, N., Hukkinen, J.I., Kuusinen, N.J., Räisänen, P., Valsta, L.T., 2016. Nudging service providers and assessing service trade-offs to reduce the social inefficiencies of payments for ecosystem services schemes. Env. Sci. Pol. 55, 228-237.

MEA, 2005. Millennium Ecosystem Assessment. Ecosystems and human well-being: biodiversity synthesis. World resources institute, Washington, DC.

Miina, J., Pukkala, T., Kurttila, M., 2016. Optimal multi-product management of stands producing timber and wild berries. Eur. J. For. Res. 135, 781-794. 
803

804

805

806

807

808

809

810

811

812

813

814

815

816

817

818

819

820

821

822

823

824

825

826

Moilanen, A., 2007. Landscape zonation, benefit functions and target-based planning: unifying reserve selection strategies. Biol. Conserv. 134, 571-579.

Moilanen, A., Wintle, B.A., 2007. The boundary-quality penalty: a quantitative method for approximating species responses to fragmentation in reserve selection. Conserv. Biol. 21, 355364.

Moilanen, A., Anderson, B.J., Eigenbrod, F., Heinemeyer, A., Roy, D.B., Gillings, S., Armsworth, P.R., Gaston, K.J., Thomas, C.D., 2011. Balancing alternative land uses in conservation prioritization. Ecol. Appl. 21, 1419-1426.

Moilanen, A., Pouzols, F.M., Meller, L., Veach, V., Arponen, A., Leppänen, J., Kujala, H., 2014. Zonation - Spatial conservation planning methods and software. Version 4. User Manual. http://cbig.it.helsinki.fi/files/zonation/zonation manual v4 0.pdf (accessed 05.08.16).

Mononen, L., Vihervaara, P., Repo, T., Korhonen, K.T., Ihalainen, A., Kumpula, T., 2017. Comparative study on biophysical ecosystem service mapping methods - a test case of carbon stocks in Finnish Forest Lapland. Ecol. Ind. 73, 544-553.

National Land Survey of Finland, 2015. File service of open data. https://tiedostopalvelu.maanmittauslaitos.fi/tp/kartta?lang=en (accessed 10.11.15).

Natural Resources Institute Finland, 2016. File service for publicly available data. http://kartta.metla.fi/index-en.html (accessed 04.02.16).

Nelson, E., Mendoza, G., Regetz, J., Polasky, S., Tallis, H., Cameron, D., Chan, K.M.A., Daily, G.C., Goldstein, J., Kareiva, P.M., Lonsdorf, E., Naidoo, R., Ricketts, T.H., Shaw, M.R., 2009. Modeling multiple ecosystem services, biodiversity conservation, commodity production, and tradeoffs at landscape scales. Frontiers Ecol. Env. 7: 4-11.

Packalén, P., Heinonen, T., Pukkala, T., Vauhkonen, J., Maltamo, M., 2011. Dynamic treatment units in Eucalyptus plantation. For. Sci. 57, 416-426. 
Puddister, D., Dominy, S.W.J., Baker, J.A., Morris, D.M., Maure, J., Rice, J.A., Jones, T.A., Majumdar, I., Hazlett, P.W., Titus, B.D., Fleming, R.L., Wetzel, S., 2011. Opportunities and challenges for Ontario's forest bioeconomy. For. Chron. 87, 468-477.

Pukkala, T., 2005. Metsikön tuottoarvon ennustemallit kivennäismaan männiköille, kuusikoille ja rauduskoivikoille (in Finnish for "Prediction models for the expectation value of pine, spruce and birch stands on mineral soils"). Metsätieteen Aikakauskirja 3/2005, 311-322.

Pukkala, T., 2008. Integrating multiple services in the numerical analysis of landscape design, in: von Gadow, K., Pukkala, T. (Eds.), Designing Green Landscapes. Managing Forest Ecosystems 15, Springer, Dordrecht, pp. 137-167.

Pukkala, T., 2014. Does biofuel harvesting and continuous cover management increase carbon sequestration?. For. Pol. Econ. 43, 41-50.

Pukkala, T., 2016. Which type of forest management provides most ecosystem services?. For. Ecosystems, 3:9. doi: 10.1186/s40663-016-0068-5

Pukkala, T., Kangas, J., 1993. A heuristic optimization method for forest planning and decision making. Scand. J. For. Res. 8, 560-570.

Pukkala, T., Kellomäki, S., Mustonen, E., 1988. Prediction of the amenity of a tree stand. Scand. J. For. Res. 3, 533-544.

Pukkala, T., Nuutinen, T., Kangas, J., 1995. Integrating scenic and recreational amenities into numerical forest planning. Landscape Urban Plan. 32, 185-195.

R Core Team, 2016. R: A language and environment for statistical computing. R Foundation for Statistical Computing, Vienna, https://www.R-project.org/ (accessed 05.08.16).

Räsänen, A., Lensu, A., Tomppo, E., Kuitunen, M., 2015. Comparing conservation value maps and mapping methods in a rural landscape in Southern Finland. Landscape Online 44, 1-19.

Sani, N.A., Kafaky, S.B., Pukkala, T., Mataji A., 2016. Integrated use of GIS, remote sensing and multicriteria decision analysis to assess ecological land suitability in multi-functional forestry. J. For. Res., doi: 10.1007/s11676-016-0242-1 
853

854

855

856

857

858

859

860

861

862

863

864

865

866

867

868

869

870

871

872

873

874

875

876

877

Schröter, M., Rusch, G.M., Barton, D.N., Blumentrath, S., Nordén, B., 2014. Ecosystem services and opportunity costs shift spatial priorities for conserving forest biodiversity. PLOS ONE 9(11), e112557, doi:10.1371/journal.pone.0112557

Schulp, C.J.E., Burkhard, B., Maes, J., Van Vliet, J., Verburg, P.H., 2014. Uncertainties in ecosystem service maps: a comparison on the European scale. PLoS ONE 9(10), e109643, doi: 10.1371/journal.pone.0109643

Schwenk, W.S., Donovan, T.M., Keeton, W.S., Nunery, J.S., 2012. Carbon storage, timber production, and biodiversity: comparing ecosystem services with multi-criteria decision analysis. Ecol. Appl. 22, 1612-1627.

Sievänen, T., Neuvonen, M. (Eds.), 2011. Luonnon virkistyskäyttö 2010 (in Finnish for "The recreational use of nature in 2010"). Working Papers of the Finnish Forest Research Institute 212, ISBN 978-951-40-2332-3. 190 p. http://www.metla.fi/julkaisut/workingpapers/2011/mwp212.htm (accessed 05.08.16).

Silvennoinen, H., Pukkala, T., Tahvanainen, L., 2002. Effect of cuttings on the scenic beauty of a tree stand. Scand. J. For. Res. 17, 263-273.

Store, R., Kangas, J., 2001. Integrating spatial multi-criteria evaluation and expert knowledge for GISbased habitat suitability modelling. Landscape Urban Plan. 55, 79-93.

Strimas-Mackey, M., 2016. Field guide to ILP solvers in R for conservation prioritization. Web page, http://strimas.com/prioritization/ilp-field-guide/ (accessed 28.11.16).

Thomas, S.C., Martin, A.R., 2012. Carbon content of tree tissues: a synthesis. Forests 3, 332-352.

Tomppo, E., Halme, M., 2004. Using coarse scale forest variables as ancillary information and weighting of variables in k-NN estimation: a genetic algorithm approach. Remote Sens. Environ. 92, 1-20.

Tomppo, E., Haakana, M., Katila, M., Peräsaari, J., 2008a. Multi-source national forest inventory Methods and applications. Managing Forest Ecosystems 18, Springer, Dordrecht. 374 p. 
878 Tomppo, E., Olsson, H., Ståhl, G., Nilsson, M., Hagner, O., Katila, M., 2008b. Combining national 879 forest inventory field plots and remote sensing data for forest databases. Remote Sens. $880 \quad$ Environ. 112, 1982-1999.

Tomppo, E., Katila, M., Mäkisara, K., Peräsaari, J., 2014. The multi-source national forest inventory of Finland - methods and results 2011. Working Papers of the Finnish Forest Research Institute 319. 224 p. http://www.metla.fi/julkaisut/workingpapers/2014/mwp319.htm (accessed 05.08.16).

Triviño, M., Juutinen, A., Mazziotta, A., Miettinen, K., Podkopaev, D., Reunanen, P., Mönkkönen, M., 2015. Managing a boreal forest landscape for providing timber, storing and sequestering carbon. Ecosystem Serv. 14, 179-189.

Troy, A., Wilson, M.A., 2006. Mapping ecosystem services: Practical challenges and opportunities in linking GIS and value transfer. Ecol. Econ. 60, 435-449.

Tuominen, S., Eerikäinen, K., Schibalski, A., Haakana, M., Lehtonen, A., 2010. Mapping biomass variables with a multi-source forest inventory technique. Silva Fenn. 44, 109-119.

Uhde, B., Hahn, W.A., Griess, V.C., Knoke, T., 2015. Hybrid MCDA methods to integrate multiple ecosystem services in forest management planning: A critical review. Env. Manage. 56, 373388.

Vatka, E., Kangas, K., Orell, M., Lampila, S., Nikula, A., Nivala, V., 2014. Nest site selection of a primary hole-nesting passerine reveals means to developing sustainable forestry. J. Avian Biol.

Wunder, S., Jellesmark Thorsen, B., 2014. What are ecosystem services?, in: Thorsen, B.J., Mavsar, 45, 187-196.

Vauhkonen, J., Pukkala, T., 2016. Selecting the trees to be harvested based on the relative value growth of the remaining trees. Eur. J. For. Res. 135, 581-592. R., Tyrväinen, L., Prokofieva, I., Stenger, A. (Eds.), The Provision of Forest Ecosystem Services. Volume I: Quantifying and valuing non-marketed ecosystem services. What Science Can Tell Us 5, European Forest Institute, ISBN 978-952-5980-13-4, pp. 17-20. 
TABLES

906

907

Table 1. Forest ecosystem services considered by our study, categorized according to MEA (2005).

\begin{tabular}{|c|c|c|}
\hline & & Stand-level forest attributes used for \\
\hline Category & Example service (indicator; unit) & modeling the indicator values (citation) \\
\hline Supporting service & $\begin{array}{l}\text { Biodiversity management } \\
\text { (conservation value based on } \\
\text { expert opinion; index value) }\end{array}$ & $\begin{array}{l}\text { Species composition, mean diameter, } \\
\text { growing stock volume, site fertility } \\
\text { (Lehtomäki et al., 2015) }\end{array}$ \\
\hline Provisioning service & $\begin{array}{l}\text { Timber production (soil } \\
\text { expectation value; } € / \text { ha) }\end{array}$ & $\begin{array}{l}\text { Mean diameter, basal area, age, site } \\
\text { fertility, species-specific growing stock } \\
\text { volume, number of trees, operational } \\
\text { environment (temperature, interest rate, } \\
\text { timber prices) (Pukkala, 2005) }\end{array}$ \\
\hline Regulating service & $\begin{array}{l}\text { Carbon storage (estimated } \\
\text { amount of carbon; } t / h a)\end{array}$ & $\begin{array}{l}\text { Total biomass converted to carbon (IPCC, } \\
\text { 2003) }\end{array}$ \\
\hline Cultural service & $\begin{array}{l}\text { Recreational value (recreational } \\
\text { amenity and suitability for berry } \\
\text { picking; index values) }\end{array}$ & $\begin{array}{l}\text { Mean diameter, basal area, age, } \\
\text { site fertility, species-specific growing } \\
\text { stock volume, number of trees (Pukkala } \\
\text { et al., 1988; Ihalainen et al., 2002) }\end{array}$ \\
\hline
\end{tabular}


910 Table 2. Central characteristics of the forest inventory data for the 27,575 pixels considered in the 911 analyses. SD - standard deviation.

912

\begin{tabular}{lccc}
\hline Attribute & Mean & SD & Range \\
\hline Total volume, $\mathrm{m}^{3} / \mathrm{ha}$ & 193.0 & 66.6 & $0-442$ \\
- Pine volume, $\mathrm{m}^{3} / \mathrm{ha}$ & 65.7 & 37.0 & $0-212$ \\
- Spruce volume, $\mathrm{m}^{3} / \mathrm{ha}$ & 94.6 & 69.8 & $0-372$ \\
- Deciduous volume, $\mathrm{m}^{3} / \mathrm{ha}$ & 32.7 & 18.1 & $0-132$ \\
Total biomass, $\mathrm{t} / \mathrm{ha}$ & 131.4 & 42.0 & $0-274$ \\
Basal area, $\mathrm{m}^{2} / \mathrm{ha}$ & 21.7 & 5.6 & $0-35$ \\
Age, years & 58.0 & 17.3 & $1-115$ \\
Diameter, $\mathrm{cm}$ & 20.1 & 5.5 & $0-35$ \\
Dominant height, $\mathrm{m}$ & 20.1 & 7.2 & $3-35$ \\
\hline
\end{tabular}

913

914 
915 Table 3. Spatial conflicts between the ESs as the percentage of the overlapping pixels. The upper-

916 right and lower-left fields, with respect to the diagonal marked by asterisks $\left({ }^{* *}\right)$, present the values

917 for the most important $10 \%$ and $30 \%$ of the pixels, respectively.

918

\begin{tabular}{lcccc}
\hline ES & Biodiversity & Timber & Carbon & Recreation \\
\hline Biodiversity & $* *$ & 16.6 & 24.4 & 30.7 \\
Timber & 46.8 & $* *$ & 66.5 & 25.5 \\
Carbon & 48.8 & 78.0 & $* *$ & 30.8 \\
Recreation & 50.1 & 45.5 & 52.5 & $* *$ \\
\hline
\end{tabular}

919

920 
921 FIGURES

922

923 Figure 1. The most suitable ES selected according to the highest priority value per pixel.

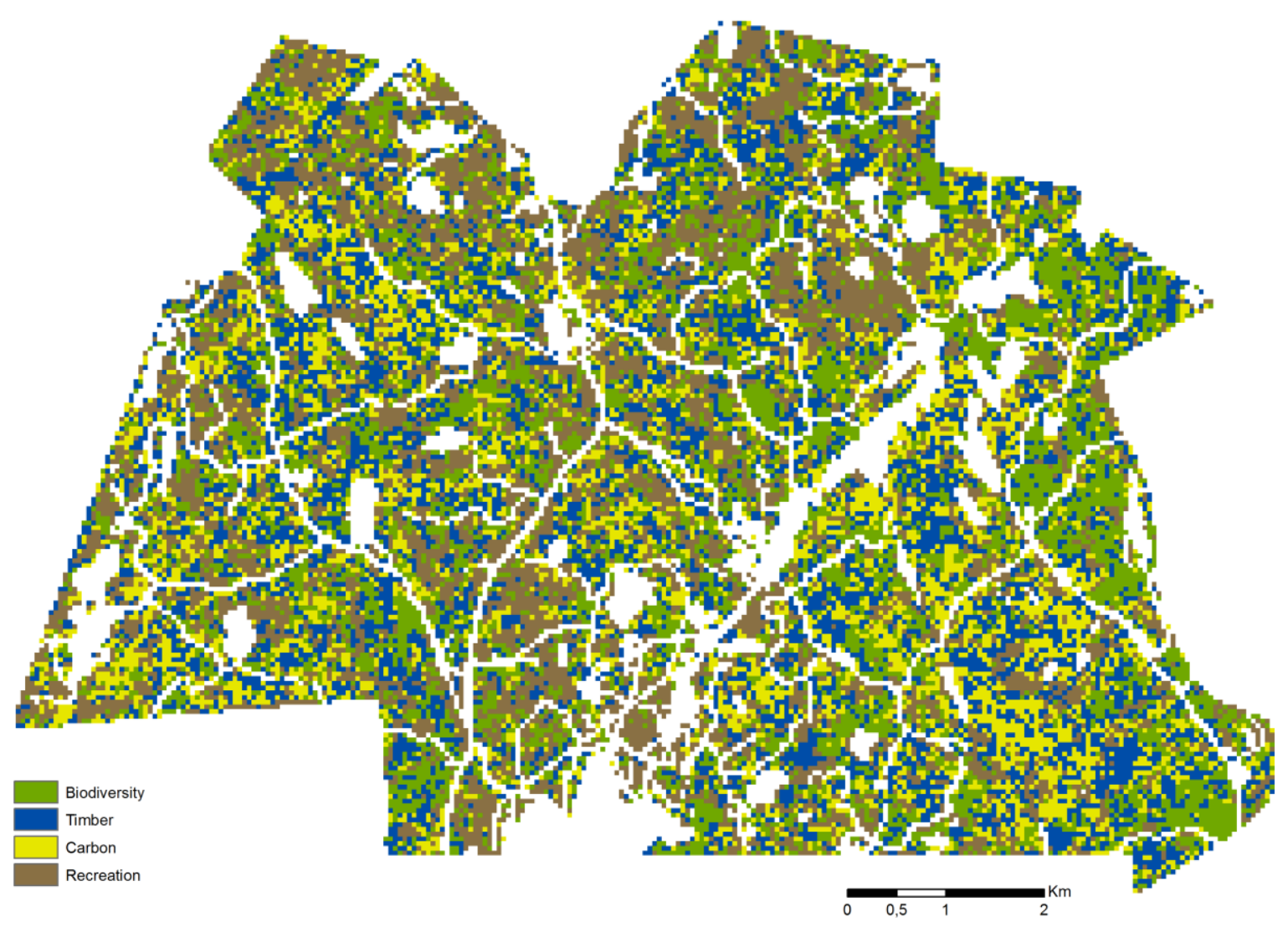


927

Figure 2. Effects of applying Boundary Length Penalty (BLP) in Eq. 1 to the priority values of the ESs in the entire landscape. Above: the spatial overlap of pixels with the top priority fraction given in the $\mathrm{x}$-axis between the non-spatial and spatial solution using a BLP value of 0.01. Below: the mean and standard deviation of the overlap, when the value of the BLP parameter was increased.
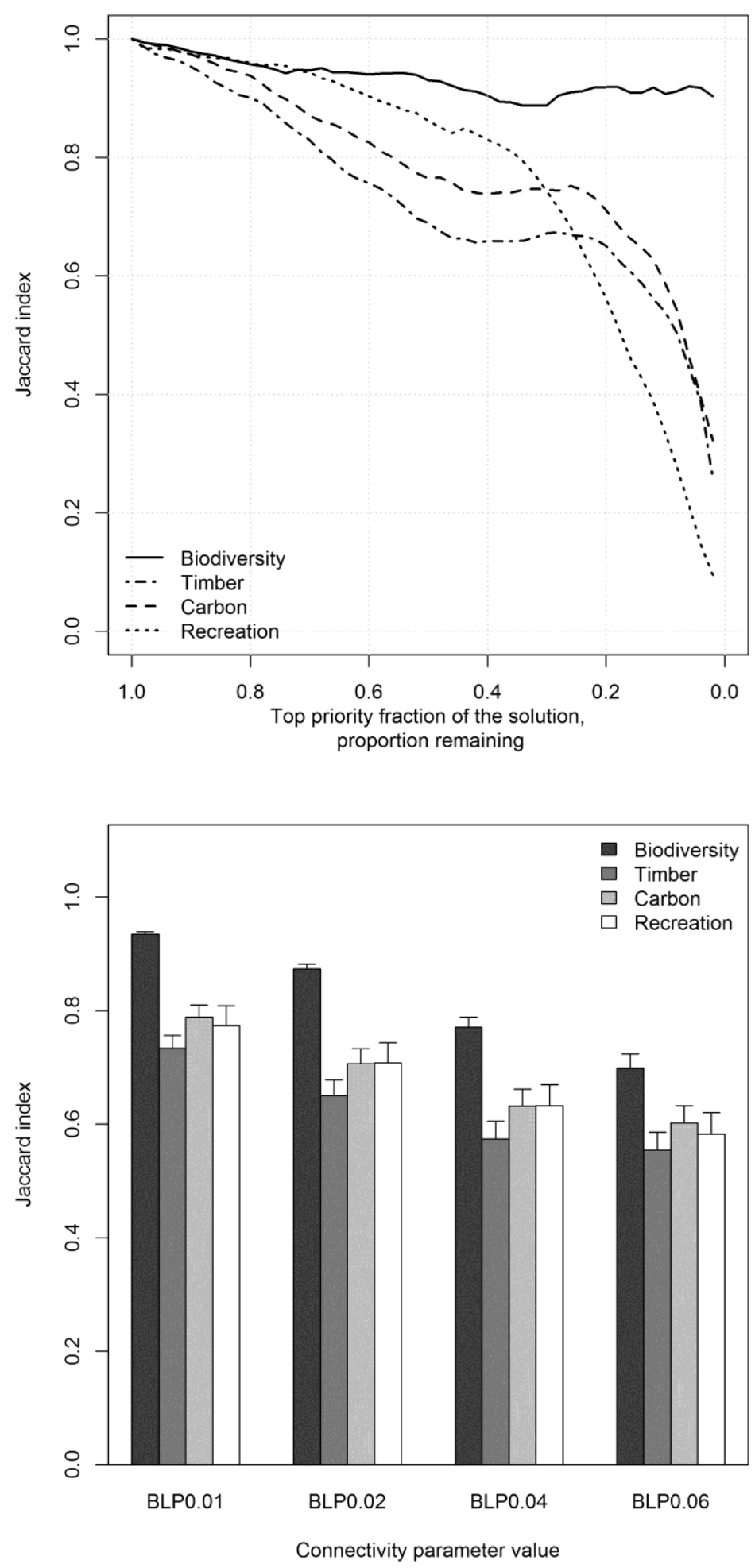
933 Figure 3. Effects of prioritizing the management of the landscape according to an ES to all the ESs considered. The $y$-axis shows the proportion of the ESs remaining, when the pixels are prioritized for the ES indicated in the title of each subplot and a fraction of least important pixels indicated by the $x$-axis is removed from the full landscape.

a) Biodiversity
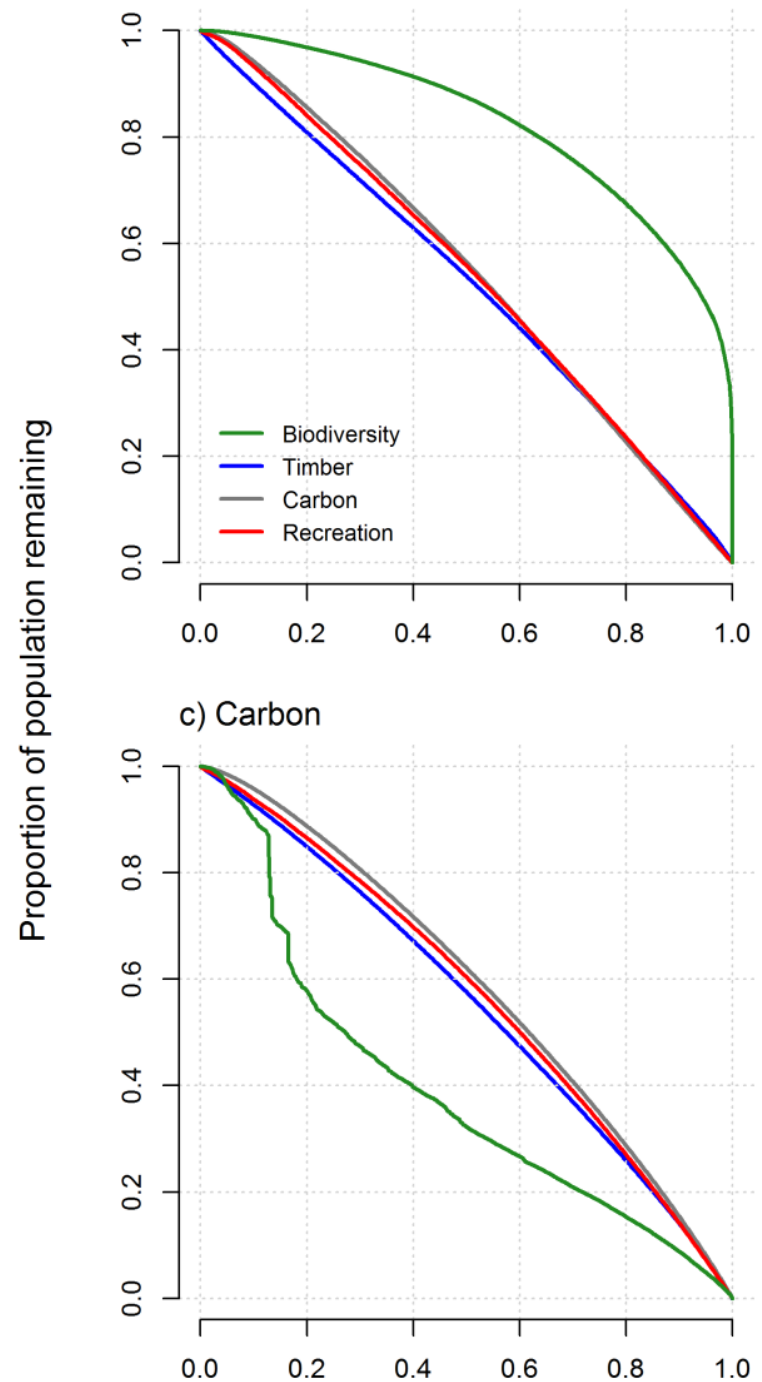

b) Timber

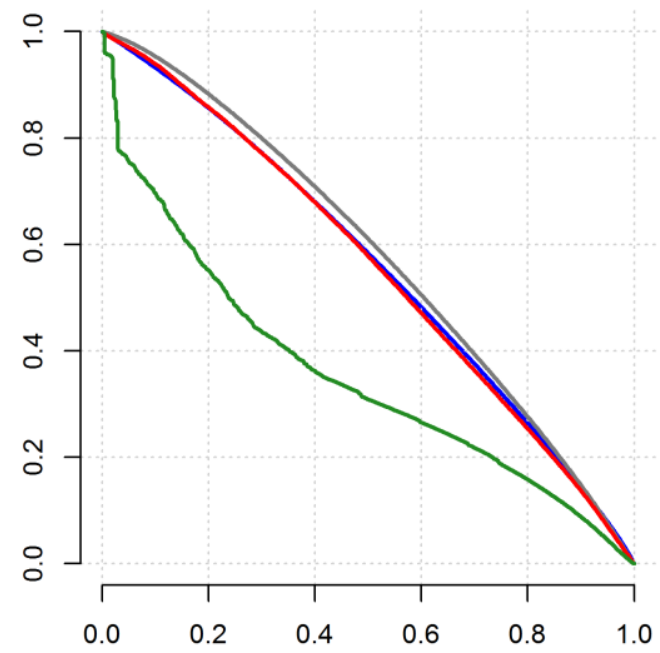

d) Recreation

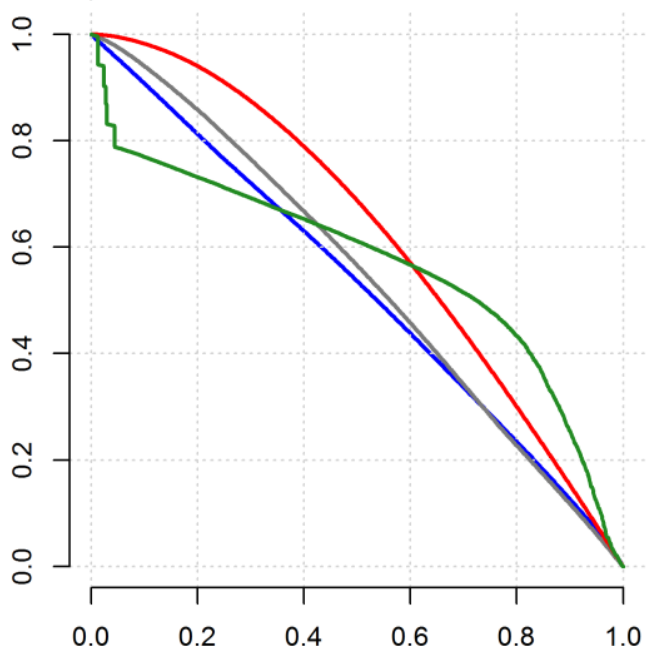


Figure 4. Performance curves corresponding to Figure 3, when the allocation of the ESs was balanced and included in a single run.

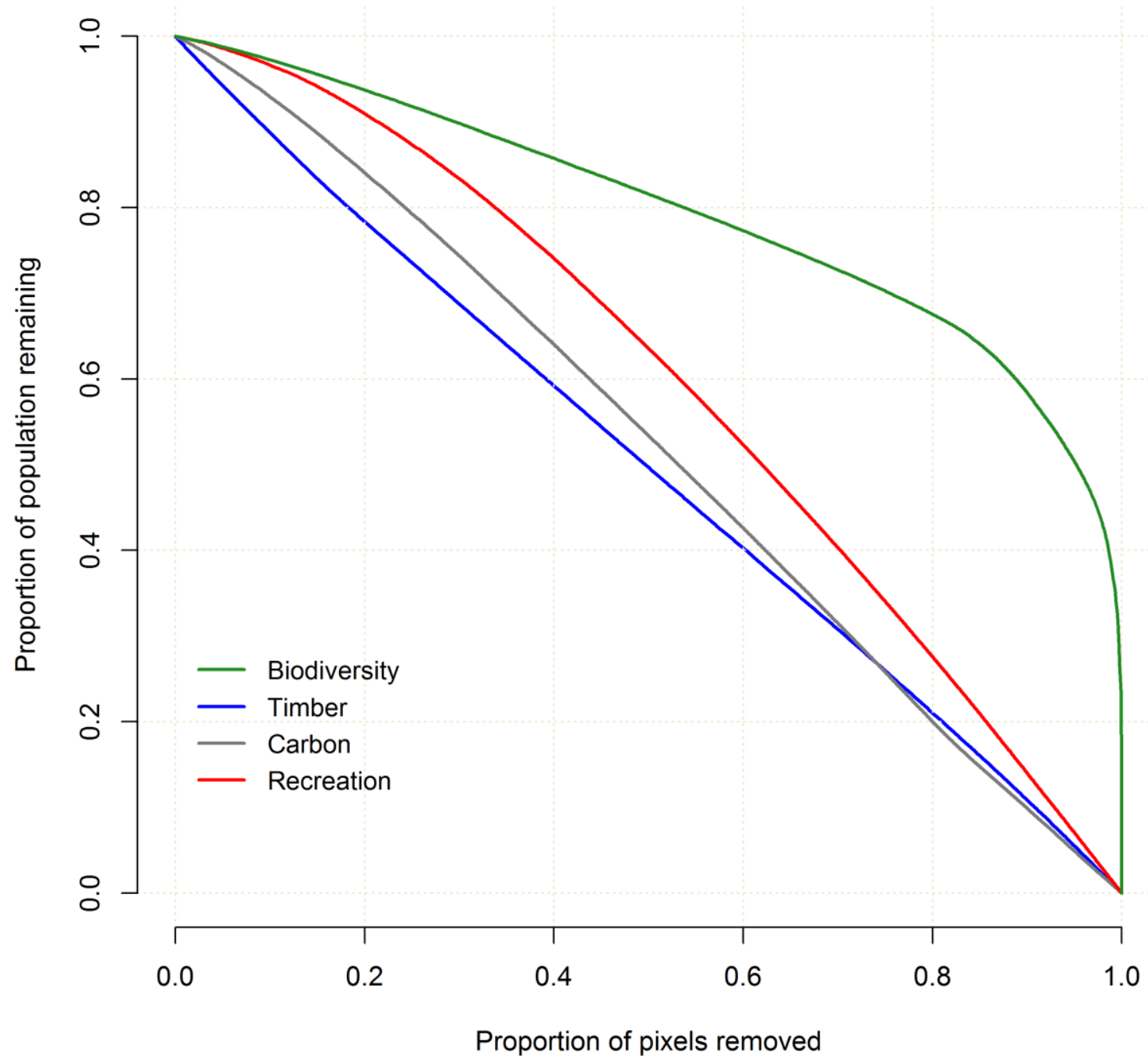

941 
943 Figure 5. Spatial distribution of the most important 30\% of the sites for the ESs.

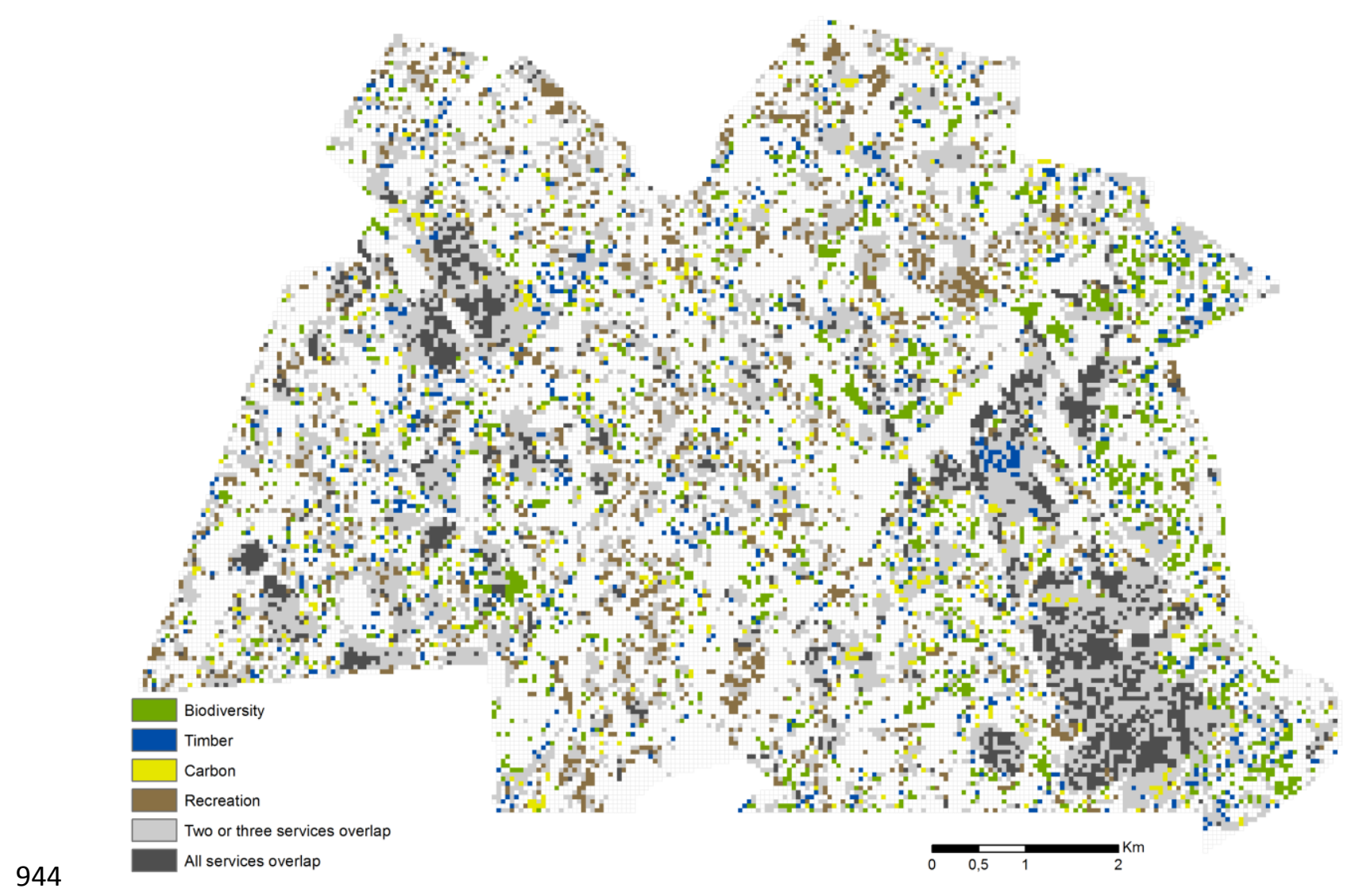


947 Figure 6. The distribution of mean age (a), mean diameter (b), dominant height (c), number of trees

948 per hectare (d), number of individual species (e), and proportions of dominant (f), coniferous (g) and

949 deciduous species ( $h$ ) in Ecosystem Service Potential (ESP) classes given in the $\mathrm{x}$-axis. Altogether 59

950 observations had a number of trees higher than the scale of (d) and are thus not shown.
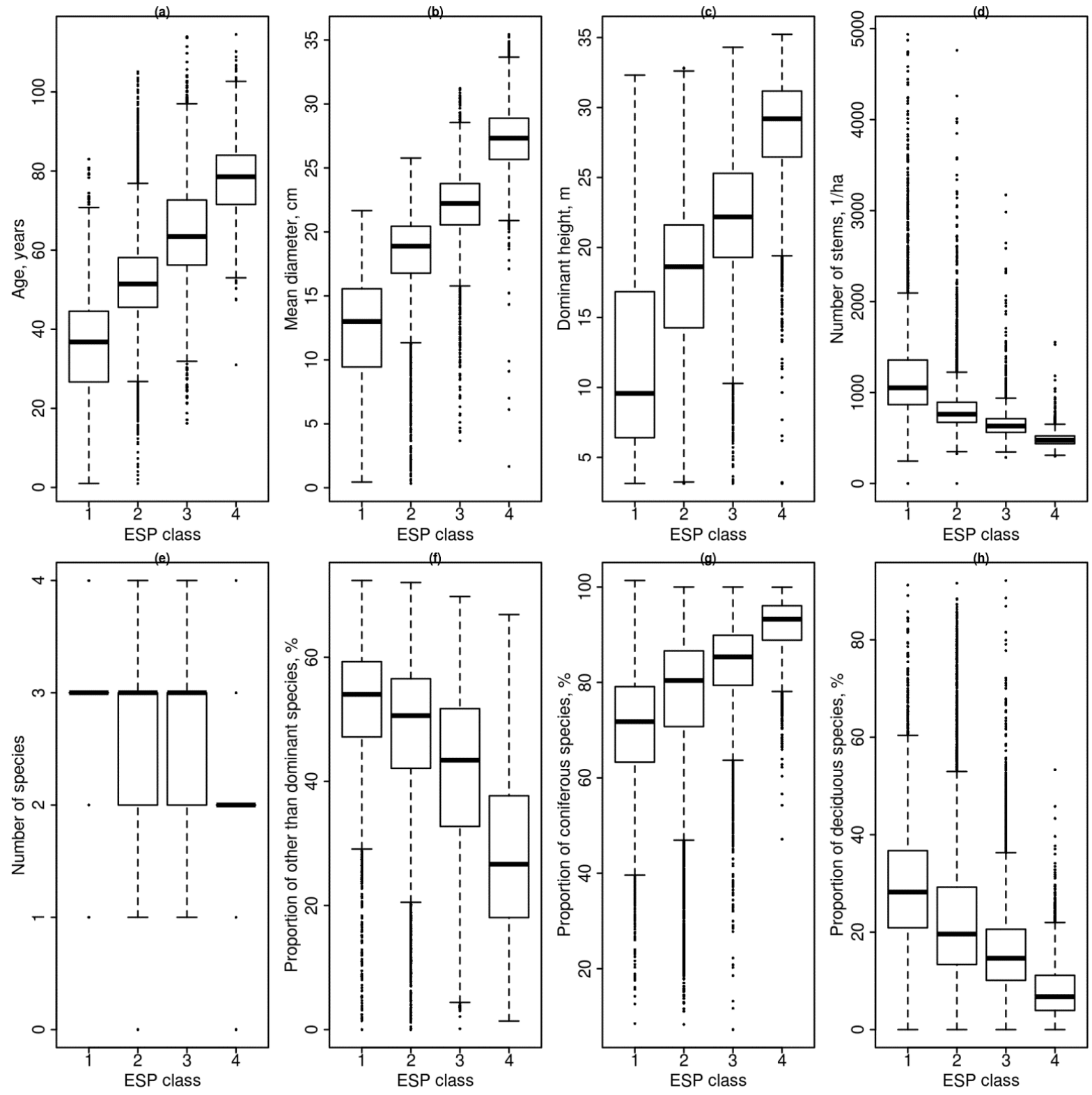
953

954

955

956

957 the small number of observations.
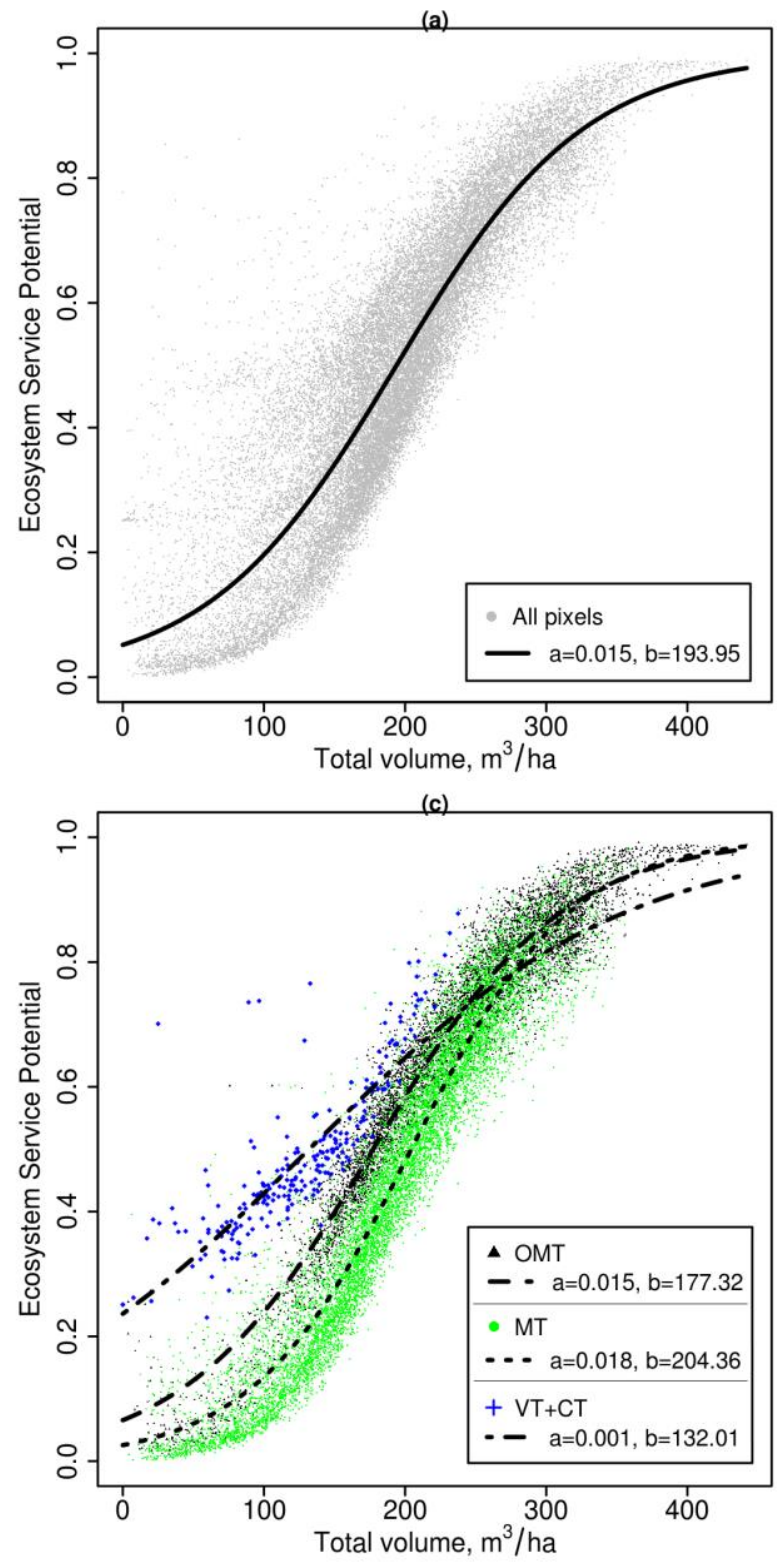

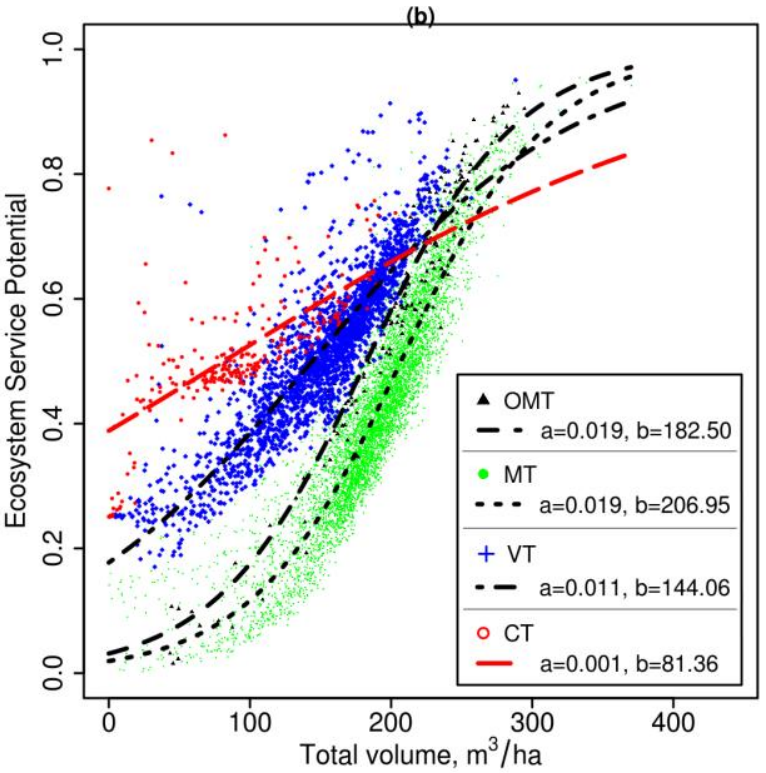

(d)

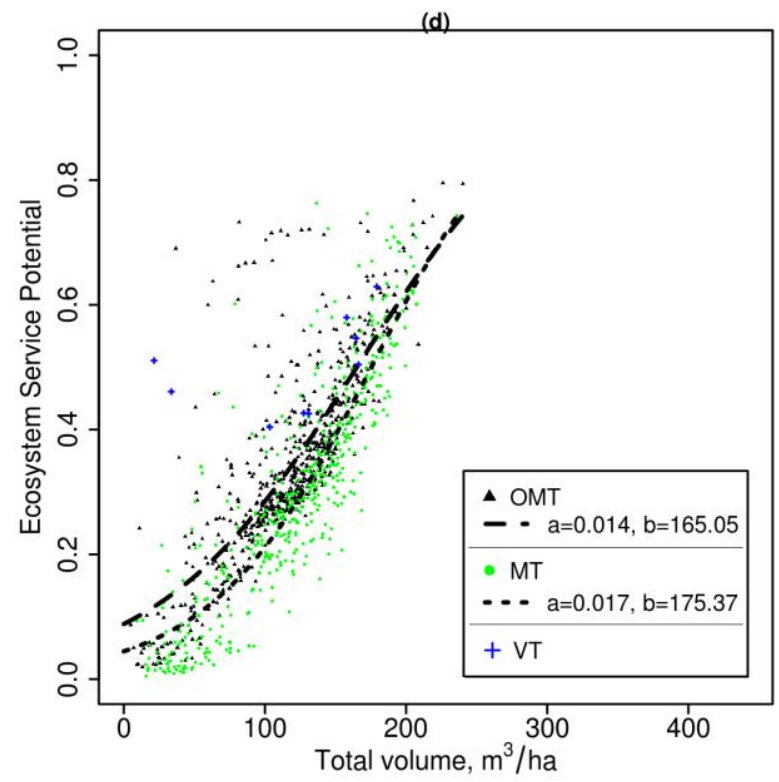

Figure 7. Pixel-wise ESP values as a function of the stem volume in the entire data (a) and pixels dominated by pine (b), spruce (c) and deciduous species (d). The lines indicate the fit of Eq. 4 based on the estimated values of $a$ and $b$ according to the site fertility classes (OMT - Oxalis-Myrtillus type, MT - Myrtillus type, VT - Vaccinium type, CT - Cladonia type). Eq. 4 was not fit for VT in (d) due to 
960 Figure 8. Tradeoffs between the ESs in the landscape, illustrated as alternative production levels of

961 timber and carbon storage. The curves were produced selecting the timber production sites in

962 different ways as the $\mathrm{X} \%$ of the least important pixels, where the character symbols indicate $\mathrm{X}$ in

$96310 \%$ intervals. "Optimized" refers to the optimized selection of the timber production sites with a

964 constraint to retain X\% of the most important sites for carbon storage. "Selected" and "Balanced"

965 refer to the corresponding selection according to the priority maps derived for biodiversity or

966 recreation (curves overlap) and using the balanced weighting (Section 2.4.), respectively. The

967 asterisk (*) shows the position of the most suitable ES selected according to the highest priority

968 value per pixel (cf., Figure 1).

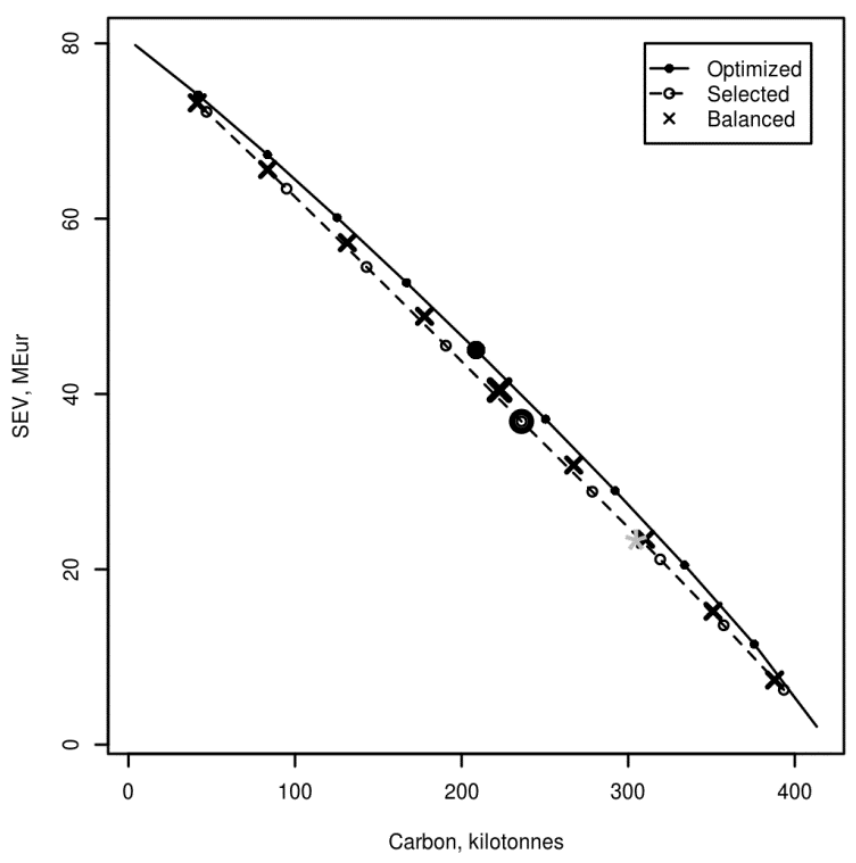

969 